\title{
An immune-humanized patient-derived xenograft model of estrogen-independent, hormone receptor positive metastatic breast cancer
}

\author{
Sandra D. Scherer ${ }^{1,2}$, Alessandra I. Riggio 1,2, Fadi Haroun 1,2, Yoko S. DeRose ${ }^{1,2}$, H. Atakan Ekiz ${ }^{1,2}$, Maihi Fujita ${ }^{1,2}$,
} Jennifer Toner ${ }^{1,2}$, Ling Zhao ${ }^{1,2}$, Zheqi Li ${ }^{3}$, Steffi Oesterreich ${ }^{3}$, Ahmed A. Samatar ${ }^{4}$ and Alana L. Welm ${ }^{1,2^{*}}$ (0)

\begin{abstract}
Background: Metastatic breast cancer (MBC) is incurable, with a 5 -year survival rate of $28 \%$. In the USA, more than 42,000 patients die from MBC every year. The most common type of breast cancer is estrogen receptor-positive $(E R+)$, and more patients die from ER+ breast cancer than from any other subtype. ER+ tumors can be successfully treated with hormone therapy, but many tumors acquire endocrine resistance, at which point treatment options are limited. There is an urgent need for model systems that better represent human ER+ MBC in vivo, where tumors can metastasize. Patient-derived xenografts (PDX) made from MBC spontaneously metastasize, but the immunodeficient host is a caveat, given the known role of the immune system in tumor progression and response to therapy. Thus, we attempted to develop an immune-humanized PDX model of ER+ MBC.
\end{abstract}

Methods: NSG-SGM3 mice were immune-humanized with CD34+ hematopoietic stem cells, followed by engraftment of human ER+ endocrine resistant MBC tumor fragments. Strategies for exogenous estrogen supplementation were compared, and immune-humanization in blood, bone marrow, spleen, and tumors was assessed by flow cytometry and tissue immunostaining. Characterization of the new model includes assessment of the human tumor microenvironment performed by immunostaining.

Results: We describe the development of an immune-humanized PDX model of estrogen-independent endocrine resistant ER+ MBC. Importantly, our model harbors a naturally occurring ESR1 mutation, and immune-humanization recapitulates the lymphocyte-excluded and myeloid-rich tumor microenvironment of human ER+ breast tumors.

Conclusion: This model sets the stage for development of other clinically relevant models of human breast cancer and should allow future studies on mechanisms of endocrine resistance and tumor-immune interactions in an immune-humanized in vivo setting.

Keywords: ER+ metastatic breast cancer, ER+ PDX, Humanized PDX, Immune-humanization, ESR1 mutation, Y537S, Endocrine resistance model, Estrogen supplementation, Breast cancer tumor microenvironment

*Correspondence: alana.welm@hci.utah.edu

1 Department of Oncological Sciences, University of Utah, 2000 Circle of Hope, Salt Lake City, UT 84112, USA

Full list of author information is available at the end of the article

\section{Background}

Breast cancer is the second leading cause of cancerrelated deaths in women worldwide [1]. With an estimated 276,480 newly diagnosed cases in the USA alone, breast cancer is the most frequently diagnosed original author(s) and the source, provide a link to the Creative Commons licence, and indicate if changes were made. The images or other third party material in this article are included in the article's Creative Commons licence, unless indicated otherwise in a credit line to the material. If material is not included in the article's Creative Commons licence and your intended use is not permitted by statutory regulation or exceeds the permitted use, you will need to obtain permission directly from the copyright holder. To view a copy of this licence, visit http://creativecommons.org/licenses/by/4.0/. The Creative Commons Public Domain Dedication waiver (http://creativeco mmons.org/publicdomain/zero/1.0/) applies to the data made available in this article, unless otherwise stated in a credit line to the data. 
malignancy in women. Between 25 and 30\% of these breast cancer patients develop metastases, at which point the disease becomes incurable, and more than 42,000 patients die each year. Clinically, breast cancer is categorized into three major subtypes: (1) hormone receptor-positive, which refers to the presence of the estrogen receptor alpha (ER, encoded by the gene ESR1) and/or progesterone receptor (PR); (2) human epidermal growth factor receptor 2 (HER2)-positive, which refers to the overexpression of HER2 due to amplification of the ERBB2 locus; and (3) triple negative breast cancer (TNBC), which lacks expression of the above-mentioned markers [2]. The majority of breast cancers are hormone receptor-positive, with nearly $75 \%$ expressing ER [1, 3]. While short-term survival rates of ER+ breast cancer patients are higher than in other subtypes, such as TNBC, more patients die from ER+ breast cancer than from any other subtype. Hence, there is an urgent need to discover and develop novel effective therapies for ER+ metastatic breast cancer (MBC).

Spreading of the tumor to distant organs, or metastasis, has fatal consequences and is the cause of most breast cancer deaths. While ER+ breast cancer can be treated with endocrine (hormone) therapy, metastatic tumors often develop endocrine resistance. The most commonly used endocrine therapies for ER+ MBC are selective estrogen receptor degraders (SERDs), selective estrogen receptor modulators, and aromatase inhibitors [4], with aromatases being key enzymes for the conversion of androgens into estrogens. Once ER+ tumors have metastasized and become endocrine resistant, effective treatments are limited. One established mechanism of endocrine resistance that limits treatment options is the acquisition of mutations in ESR1, which render the ER protein less dependent on estrogen for its function $[5,6]$. ESR1 mutations occur almost exclusively in metastatic disease that recurs after endocrine therapy, the most common ESR1 mutations cause ER to retain an active conformation without estrogen binding [5-7]. In addition, breast cancers with ESR1 mutations can gain a basal-like gene expression profile and enhanced M2-like macrophage immune activation that is associated with poor prognosis [8].

Reliable model systems that recapitulate patients' disease are fundamental for drug development with the goal to achieve better translatability into the clinic. However, models of human ER+ MBC are limited. Human breast cancer cell lines including T47D [9], MCF7 [9], and MDA-MB-231 [10] have been extensively studied, and have been engineered to have ESR1 mutations. Others have generated breast cancer cell lines from patientderived xenograft (PDX) models [11]. In response to the need for models that better recapitulate patient tumors, represent the wide range of inter-patient heterogeneity, and are reflective of today's treatment paradigms, however, several ER + PDX models have been developed [12-15]. PDX models resemble the patient's disease on a genomic, molecular, and cellular level [12, 15-19], and are therefore valuable tools for research.

One caveat of PDX models is that they are grown in immunodeficient mouse strains, and therefore lack a functional immune system. It is well established that the tumor microenvironment is involved in various stages of solid tumor progression and metastasis [20-23] and, importantly, can influence treatment outcome and drug resistance [24-26]. In breast cancer, $\mathrm{T}$ cell infiltration is dynamic and heterogenous, and $\mathrm{T}$ cells are often excluded from tumors due to an immunosuppressive microenvironment, rendering immunotherapy largely ineffective [27]. On the other hand, myeloid cells robustly infiltrate breast tumors and are important for pro-tumorigenic effects [28]. Cells of the myeloid lineage, such as tumorassociated macrophages (TAMs), have been shown to play a fundamental role in disease progression. In breast cancer, the most dominant macrophage types are TAMs with a tumor-promoting "M2-like" phenotype [29], and high TAM infiltration correlates with poor prognosis [30, 31]. TAMs can negatively influence the efficacy of PARP inhibitors [24] and, in ER+ human breast cancer cell lines, TAMs have been implicated in resistance to endocrine therapy [32]. Taken together, these data underscore the importance of generating immune-humanized models for ER+ breast cancer to better define tumor-host interactions and improve patient outcome by uncovering strategies to make this disease more responsive to immunotherapy.

Immune-humanization of mice has been previously described [33], and such mice have been utilized in xenograft studies using human breast cancer cell lines [34-36] or TNBC PDXs [37]. However, immune-humanized ER+ PDXs have not been yet been reported. Thus, we sought to generate an immune-humanized PDX model of ER+ disease for which treatments are urgently needed: endocrine-resistant $\mathrm{MBC}$ with a naturally occurring ESR1 mutation. Importantly, we found that immune-humanization of this breast cancer subtype recapitulates the lymphocyte-sparse and myeloid-rich immune milieu of certain human ER+ breast tumors: over $15 \%$ of luminal B breast cancers have been reported to display a lymphocyte-depleted milieu [38].

\section{Methods}

Experimental animals and health monitoring

All procedures were approved by the University of Utah Institutional Animal Care and Use Committee (IACUC). NSG mice (NOD.Cg-Prkdcscid Il2rgtm1Wjl/ 
SzJ) or NSG-SGM3 mice (NOD.Cg-Prkdcscid Il2rgtm1Wjl Tg(CMV-IL3,CSF2,KITLG)1Eav/MloySzJ) were purchased from Jackson Laboratories one week before the beginning of an experiment and received $4100 \mathrm{ppm}$ Uniprim Diet (3980X, 2\% maltodextrin, TD cat. \#200733) from Envigo upon arrival. Two days after arrival and throughout the entire experiment, mice received acidified drinking water and were supplemented with gel diet 76A (Clear H2O, cat. \# 72-07-5022). During the first 3 weeks of an experiment and in cases of weight loss, mice also received peanut butter as a supplement (Spread The Love, cat. \#B06ZXZ3JPZ) and some mice received oral antibiotic treatment with $19 \mathrm{mg} / \mathrm{kg} /$ day baytril Baytril/Enrosite (enrofloxacin). Health was monitored closely and mice weights were measured daily during the first three weeks of experiments and at least 3 times per week until the experiment ended. All procedures were performed in a sterile hood.

\section{Preparation of acidified and estrogen supplemented drinking water}

To prepare acidified drinking water, the $\mathrm{pH}$ of sterile water was adjusted to $2.8-3.0$, which was previously shown to prevent infections in experimental mice [39]. For estrogen (E2) supplementation, estrogen was added to acidified drinking water as described before [15] at a final concentration of $8 \mu \mathrm{g} / \mathrm{ml}$. Estrogen water was prepared freshly on the day of usage and changed every 3-4 days. Estrogen plasma concentrations in NSG or NSG-SGM3 mice supplemented E2 supplemented acidified drinking water is shown in Additional file 1: Fig S1.

\section{Busulfan treatment}

Busulfan (Selleck Chemicals, cat. \#S1692) was reconstituted fresh at $49 \mathrm{mg} / \mathrm{ml}$ in DMSO immediately before each usage. For complete dissolving, busulfan solution was heated to $55^{\circ} \mathrm{C}$, sonicated for 20 min and kept warm at $42{ }^{\circ} \mathrm{C}$ on a heat block. Prior to injection, busulfan was diluted in warm PBS to reduce DMSO injection to a maximum of $4 \%$ per injection. For myeloablation, mice were intraperitoneally injected with $20 \mathrm{mg} / \mathrm{kg}$ busulfan on 2 consecutive days.

\section{Injection of human HSCs}

$\mathrm{CD}^{+}{ }^{+}$hematopoietic stem cells (HSCs) isolated from healthy donor bone marrow (BM) were purchased from AllCells. On the day of injection, cells were thawed in a $37^{\circ} \mathrm{C}$ water bath and transferred into a $50 \mathrm{ml}$ conical tube. $20 \mathrm{ml}$ of warm culture media (DMEM/F12 supplemented with $10 \%$ fetal bovine serum, FBS) were slowly added dropwise into the cell suspension while gently shaking the tube. Cells were centrifuged (200 for $20 \mathrm{~min}$ at RT) and washed again in $20 \mathrm{ml}$ of culture media. After centrifugation $(200 \times g$ for $20 \mathrm{~min}$ at RT), cell pellet was resuspended in $0.5-1 \mathrm{ml}$ of HBSS and cell concentration was determined using an automated cell counter (Countess II). Cells were diluted in HBSS accordingly and kept on ice until injection. 85,000 cells were intravenously (IV) injected into experimental mice in 100 ul HBSS using a $29 \mathrm{G} \times 12.7 \mathrm{~mm}\left(1 / 2^{\prime \prime}\right)$ needle (BD Biosciences, cat. \# 324702).

\section{Implantation of breast PDX tumor tissue into mice}

HCI-013 PDX tumor fragments were implanted into the inguinal mammary fat pad (MFP) of experimental mice as previously described [40]. Briefly, tumor fragments were thawed, washed three times in warm culture media (DMEM/F12 supplemented with 10\% FBS) and kept on ice until implantation. Mice were anesthetized, the area of future incision was disinfected and PDX tumor fragments were implanted into the inguinal MFP. The fat pad posterior to the tumor implant including the area of the inguinal lymph node was cleared and the skin was closed with staples. Wound clips were removed 11-14 days post-surgery and tumors were measured twice a week using a digital caliper (9 mm, Braintree Scientific, Inc.). Tumor volume was calculated using the formula:

$$
\text { Volume }_{\text {Tumor }}=\left(\text { length } \times \text { width }{ }^{2}\right) / 2
$$

\section{Estrogen pellet implantation and monitoring in vivo estrogen levels}

Beeswax pellets containing $0.2 \mathrm{mg}$ or $0.4 \mathrm{mg}$ of E2 were prepared as published previously $[15,40]$. To implant E2 pellets into mice, the mouse was anesthetized and prepared for surgery similar to the PDX tumor implantation protocol. After an incision was made into the skin, a dull surgical forcep was then used to introduce an E2 pellet subcutaneously, contralateral to the tumor implantation site between the skin and the peritoneal wall. The E2 pellet was inserted into the pocket and the wound was closed using wound staples. To monitor systemic estrogen levels, one blood drop was obtained from the submandibular vein and plasma was isolated by centrifugation $\left(2000 \times g, 15 \mathrm{~min}, 4{ }^{\circ} \mathrm{C}\right)$. Estrogen concentrations were determined in the plasma using the Mesoscale Discovery (MSD) Custom Steroid Human Panel assay according to manufacturer's instructions. Estrogen plasma concentrations of NSG or NSG-SGM3 mice implanted with E2 pellets is shown in Additional file 1: Fig. S1.

\section{Bilateral ovariectomy and generation of $\mathrm{HCl}-013 \mathrm{EI}$}

To generate HCI-013EI, 6-8 week old NSG mice were bilaterally ovariectomized (OVX) as previously described [15]. Briefly, one hour before surgery mice were given 
buprenorphine $(0.1-0.2 \mathrm{mg} / \mathrm{kg})$. Then, the day of surgery mice were anesthetized, two dorsal incisions were made and both ovaries were removed. PDX tumor fragments were implanted and another dose of buprenorphine (0.1$0.2 \mathrm{mg} / \mathrm{kg}$ ) was given $8 \mathrm{~h}$ after the first dose. Mice were treated with carprofen $(5 \mathrm{mg} / \mathrm{kg})$ once a day for the following three days post-surgery to minimize pain. After harvesting the tumor, tumor cells were cultured for two weeks in phenol red-free HBEC medium [40] supplemented with charcoal-stripped FBS. Tumor cells were resuspended in 15 ul growth-factor reduced Matrigel per mouse, and re-implanted into the MFP in bilaterallyOVX NSG mice. No E2 supplementation was given.

\section{Tissue harvesting and processing}

All studies were performed according to IACUCapproved procedures with veterinary supervision. Tumors were harvested before exceeding the approved maximum size of $3 \mathrm{~cm}$ for studies requiring immune reconstitution, or earlier in cases when the mouse health would be compromised. On the day of necropsy, mice were euthanized and blood was immediately drawn by cardiac puncture with a syringe that was filled with 50 ul of acid-citrate-dextrose (ACD)(Sigma Aldrich cat. \#C3821). Blood was transferred into EDTA vacuum tubes (VACUETTE K2-EDTA, Greiner cat. \#454052), which were also filled with $50 \mathrm{ul} \mathrm{ACD}$, inverted twice and kept on ice. To isolate white blood cells, the blood was transferred into $15 \mathrm{ml}$ conical tubes and red blood cells (RBCs) were lysed by adding $10 \mathrm{ml}$ of $1 \times \mathrm{RBC}$ lysis buffer (Biolegend, cat. \#420301) and incubating for $10 \mathrm{~min}$ at RT. Cells were spun down and RBC lysis was repeated if necessary. White blood cells were immediately stained for flow cytometry.

Tumors and MFPs were resected. Tumors were weighed and both tumors and MFPs were fixed in 10\% NBF (neutral buffer formalin) for $24 \mathrm{~h}$ at $4{ }^{\circ} \mathrm{C}$ to generate formalin-fixed paraffin-embedded (FFPE) specimen.

Spleens were harvested and $1 / 5^{\text {th }}$ of the organ was fixed in $10 \%$ NBF $24 \mathrm{~h}$ at $4{ }^{\circ} \mathrm{C}$ to generate FFPE specimen. The remaining spleen was stored in DMEM/ F12 media supplemented with 10\% FBS and kept on ice. To generate a single cell suspension, spleens were placed onto a $70 \mu \mathrm{m}$ cell strainer (Fisher Scientific, cat. \#22363548) and mashed through it using the plunger of a $5 \mathrm{ml}$ syringe (BD, cat. \#309630). After rinsing the plunger and strainer with additional media, splenocytes were centrifuged $\left(300 \times g, 5 \mathrm{~min}, 4^{\circ} \mathrm{C}\right)$ and RBC lysis was performed on the cell pellet at least twice as described above. Splenocytes were filtered again through a $70 \mu \mathrm{m}$ cell strainer and directly stained for flow cytometry. For $\mathrm{BM}$ isolations, femur and tibia were removed and carefully cleaned from soft tissue using a scalpel. Femurs and tibiae were separated and BM was isolated by either flushing or centrifugation. To flush out the BM, both ends of the femurs and tibiae were cut off, and a $1 \mathrm{ml}$ syringe (BD, cat. \#309659) with a 26G needle (BD, 26G × 3/8, $0.45 \mathrm{~mm} \times 10 \mathrm{~mm}$, cat. \#305110) was used to scour the BM. To centrifugate BMs, the knees were removed from the leg bones by cutting right above and below the knee, as previously published [41]. Both tibia and femur were then placed into a $0.5 \mathrm{ml}$ microtube with the bottom part cut off. The microtube containing the bones was then placed into a $1.5 \mathrm{ml}$ microtube and centrifuged $(\geq 10,000 \times g, 15 \mathrm{~s}, \mathrm{RT})$. Isolated BM was resuspended and carefully broken into single cells using a pipette. Then the cell suspension was filtered through a $70 \mu \mathrm{m}$ cell strainer, $\mathrm{RBC}$ lysis was performed, and cells were stained for flow cytometry.

All FFPE tissues were fixed in $10 \%$ NBF for $24 \mathrm{~h}$ at $4{ }^{\circ} \mathrm{C}$, washed three times in PBS for $5 \mathrm{~min}$ and placed in $70 \%$ ethanol at $4{ }^{\circ} \mathrm{C}$ until tissue processing and paraffin embedding were performed. For all studies involving PDX tumor bearing animals, mice were checked for metastases in other organs, such as lungs and liver. If present, axillary lymph nodes were harvested and fixed as FFPE specimen as described above.

\section{Flow cytometry}

All flow cytometry analysis was performed using freshly isolated tissues and cells. Fc receptor blocking solution was prepared freshly by mixing a ratio of $10 \mu \mathrm{l} / 10^{7}$ cells of mouse Fc receptor blocking (Miltenyi Biotec, cat. \#130-092-575) with $15 \mu \mathrm{l} / 10^{7}$ cells of human Fc receptor blocking (Miltenyi Biotec, cat. \#130-059-901), then diluted in the same volume of FACS buffer (2\% FBS in PBS). Cells were resuspended in $50 \mu \mathrm{l}$ of Fc receptor blocking solution, transferred into a 96-well round-bottom plate (Greiner bio-one, cat. \#650101) and incubated for $20 \mathrm{~min}$ on ice. The antibody cocktail was prepared by mixing the following antibodies: $0.5 \mu \mathrm{l} /$ test BUV395 rat anti-mouse CD45 Clone 30-F11 (RUO) (BD Bioscience, cat. \#564279), $5 \mu \mathrm{l} /$ test APC mouse anti-human CD45 Clone HI30 (eBioscience, cat. \#17-0459-42), $5 \mu \mathrm{l} /$ test BV510 mouse anti-human CD11b/MAC-1 Clone ICRF44 (BD Bioscience, cat. \#563088), $2.5 \mu \mathrm{l} /$ test PE mouse antihuman CD56 (NCAM) Clone 5.1H11 (Biolegend, cat. \#362508), 5 $\mu \mathrm{l} /$ test PerCP/Cy5.5 mouse anti-human CD3 Clone UCHT1 (Biolegend, cat. \#300430), 5 $\mu \mathrm{l} /$ test FITC mouse anti-human CD19 Clone HIB19 (Biolegend, cat. \#302206). The antibody mix of $23 \mu \mathrm{l} /$ test was diluted with $27 \mu \mathrm{l} /$ test FACS buffer. $50 \mu \mathrm{l}$ of diluted antibody cocktail was added directly to each well and incubated for $30 \mathrm{~min}$ in the dark on ice. Unstained control wells received $50 \mu \mathrm{l}$ of FACS buffer. After incubation, $100 \mu$ l FACS buffer was added to each well and the plate was centrifugated 
$\left(300 \times g, 5 \mathrm{~min}, 4^{\circ} \mathrm{C}\right)$. Cell pellets were washed once with $200 \mu \mathrm{l}$ FACS buffer and once with $200 \mu \mathrm{l}$ PBS. After the last centrifugation $\left(300 \times g, 5 \mathrm{~min}, 4^{\circ} \mathrm{C}\right), 100 \mu \mathrm{l}$ of a $1: 2000$ dilution of Fixable Viability Dye eFluor ${ }^{\circledR} 780$ (eBioscience, cat \# 65-0865-18) in PBS was added to each well and incubated for $20 \mathrm{~min}$ in the dark. Unstained control wells received $100 \mu \mathrm{l}$ of PBS. After incubation, $100 \mu \mathrm{l}$ FACS buffer was added to each well and the plate was centrifuged $\left(300 \times g, 5 \mathrm{~min}, 4^{\circ} \mathrm{C}\right)$. Cell pellets were resuspended in $200 \mu \mathrm{l}$ FACS buffer, transferred into a FACS tube (Olympus Plastics, cat. \# 14-360) and stored at $4{ }^{\circ} \mathrm{C}$ with an aluminum foil cover until data acquisition.

Flow cytometry was performed immediately on freshly stained unfixed samples, and 0.5-1 million events/sample were acquired. Compensation was performed for each antibody individually using a 1:3 dilution of UltraComp eBeads ${ }^{\mathrm{TM}}$ Compensation Beads (Thermo Fisher, cat. \# 01-2222-42) in PBS. 1 drop of the bead dilution was mixed with $1 \mu \mathrm{l}$ of antibody and incubated for $20 \mathrm{~min}$ on ice in the dark. After centrifugation $\left(600 \times g, 5 \mathrm{~min}, 4{ }^{\circ} \mathrm{C}\right)$, supernatant was discarded, beads were resuspended in $200 \mu \mathrm{l}$ PBS and 5000 events were acquired. FlowJo version 10.5.3 was used for data analysis. All flow cytometry experiments included controls (FMOs,fluorescent minus one), unstained cell, and human peripheral blood mononuclear cells (PBMCs) mixed with NSG organs as positive controls for all human antibodies. Cells killed by repeated freeze/thaw cycles were used as a control for the viability staining. All gates were set based on FMO controls and the gating strategy which was applied to all samples is displayed in Additional file 1: Fig. S2.

\section{PDX tumor histology, IHC and IF stains}

FFPE specimens were sectioned by the Biorepository and Molecular Pathology Shared Resource at Huntsman Cancer Institute. To obtain serial sections of tumors, $5 \mu \mathrm{m}$ thick sections were collected, and hematoxylin-eosin (HE) staining was performed on sections every $35 \mu \mathrm{m}$ to confirm tumor content and assess morphology.

All antibodies and immunohistochemistry (IHC)/ immunofluorescence (IF) staining conditions used in this study are listed in Additional file 1: Fig. S3. Briefly, sections were incubated at $60{ }^{\circ} \mathrm{C}$ for $60 \mathrm{~min}$, deparaffinized and rehydrated following standard procedures. Antigen retrieval was performed for $20 \mathrm{~min}$ in boiling buffer in the microwave, with the following exceptions. For PHH3 and $\mathrm{CC} 3$, the water bath was used at $60{ }^{\circ} \mathrm{C} \mathrm{ON}$, and for CAM5.2 ice-cold trypsin enzymatic antigen retrieval (abcam, cat. \#ab970) was applied for $10 \mathrm{~min}$ at RT. For IHC (except for PHH3 and CC3), tissue slides were subsequently incubated in $3 \% \mathrm{H}_{2} \mathrm{O}_{2}$ methanol buffer for $10 \mathrm{~min}$ at RT to block endogenous peroxidase activity. Tissue sections were then incubated in PBS blocking buffer containing 5\% bovine serum albumin (Sigma-Aldrich, cat. \#A7906), 10\% normal goat serum (Jackson ImmunoResearch, cat. \#005-000-121), 10\% normal human serum (Jackson ImmunoResearch, cat. \#009-000-121) and FcR blocking reagents for mouse (1:100, Miltenyi Biotech, cat. \#130-092-575) and human (1:100, Miltenyi Biotech, cat. \#130-059-901) for $1 \mathrm{~h}$ at RT. In addition, if mouse primary antibodies were used, the M.O.M Immunodetection kit (Vector Labs, cat. \#BMK-2202) was added to the buffer. For double IHC and IF, the Avidin/ Biotin (Vector Labs, cat. \#SP-2001) and Streptavidin/Biotin (Vector Labs, cat. \#SP-2002) blocking kits were used, respectively. For single IHC, staining was visualized with the 3,3-diaminobenzidine-Peroxidase substrate (Vector Labs, cat. \#SK-4100), using Hematoxylin as a counterstain (Sigma-Aldrich, cat. \#MSH32). For dual IHC, VECTASTAIN ABC kit-Peroxidase HRP (Vector Labs, cat. \#PK-4000) and Vector AEC-Peroxidase substrate (Vector Labs, cat. \#SK-42000) were used for CAM5.2 visualization, whereas VECTASTAIN ABC-AP kit-Alkaline Phosphatase (Vector Labs, cat. \#AK-5000) and Vector Blue-Alkaline Phosphatase Substrate (Vector Labs, cat. \#SK-5300) were used for PHH3 and CC3 visualization. For double IF, Fluorescent Streptavidin kit (Vector Labs, cat. \#SA-1200) was used to amplify hCD45 signal. Single and double IF sections were counter-stained with the nuclear stain 4', 6-diamidino-2-phenylindole dihydro-chloride (DAPI) for $20 \mathrm{~min}$ at RT. IHC stains were mounted with the Cytoseal Mounting Medium, Richard-Allan Scientific, Iow (60 s) (VWR, cat. \#48212-154) and the VectaMount ${ }^{\mathrm{TM}}$ AQ Mounting Medium (Vector Labs, cat. \#H-5501), respectively. IF stains were mounted using the VECTASHIELD Vibrance Antifade Mounting Medium (Vector Labs, cat. \#H-1700). For each staining, secondary antibody controls were performed on serial sections.

\section{Slide digitalization and quantification}

IF and IHC tissue slides were digitalized using a Pannoramic MIDI II (3DHISTECH Ltd., Budapest, Hungary) and an Axio Scan.Z1 (ZEISS, Jena, Germany) automatic slide scanners, respectively. Automated staining quantification was done using QuPath software v0.2.3 [42]. Briefly, after uploading the images and selecting for the appropriate image type (i.e. Brightfield: H-DAB for IHC or Fluorescence for IF) (Additional file 1: Fig. S4, step 1), the brightness/contrast tool was used on the entire image to improve the visibility of the stains. Subsequently, a small annotation was drawn (Additional file 1: Fig. S4, step 2) to train the software for positive cell detection by editing the appropriate parameters based on the cellular location and the intensity of each stain (Additional file 1: Fig. S4, step 3). Following the creation of a region 
of interest (ROI) encompassing the tumor and excluding the surrounding MFP (Additional file 1: Fig. S4, step 4), the improved positive cell detection analysis was finally applied to the ROI. Extra-tumoral tissue was excluded from the analysis in order to capture intratumoral immune cells only. Snapshots and images were taken with the CaseViewer software (2.4.0.119028). For each stain, no visible signal was detected in the secondary antibody control slides.

\section{Droplet digital PCR to identify ESR1 mutations}

Droplet digital PCR (ddPCR) was performed as previously published $[15,43]$ to identify potential ESR1 hotspot mutations in HCI-013 and HCI-013EI tumors. Specifically, RLT buffer (Qiagen, cat. \# 1053393) containing beta-mercaptoethanol was added to tumor tissues which were then homogenized on ice. Immediately after, the QiagenAll Prep kit (Qiagen, cat. \# 80204) was used to isolate genomic DNA (gDNA) and total RNA following manufacturer's instructions. After cDNA synthesis using PrimeScript RT Reagent Kit (Takara, RR037), 50 ng gDNA or cDNA was used as templates and primer/probe sets for four specific ESR1 mutations (Y537S/Y537C/ Y537N/D538G) was added [43]. Droplets were generated using the Bio-Rad QX200 AutoDG Droplet Digital PCR system, followed by an amplification step of the ESR1 ligand binding domain fragment using a thermo cycler. Wildtype (WT) and mutant probes were detected with a Bio-Rad QX200 droplet reader and the allele frequency of mutant ESR1 was calculated using the QuantaSoft software version 1.7. To ensure calls were made correctly, droplets containing a positive control (gDNA from genome-edited Y537S ESR1 mutant MCF7 cell line) or negative control (gDNA from ESR1 WT MCF7 cell line), and background control $\left(\mathrm{ddH}_{2} \mathrm{O}\right)$ were included.

\section{AAVs for delivery of human cytokines}

Adeno-associated virus 9 (AAV9) vectors encoding human interleukin-7 (IL7), IL15, thrombopoietin, or empty vector controls were purchased from Vector Biosystems Inc, diluted in PBS and IV injected into mice at the following concentrations: $1.0 \times 10^{11} \mathrm{gc} / \mathrm{ml}$ AAV9CAG-h-IL7-WPRE; $2.0 \times 10^{11} \mathrm{gc} / \mathrm{ml}$ AAV9-CAG-h-IL15WPRE; $1.0 \times 10^{10} \mathrm{gc} / \mathrm{ml}$ AAV9-CAG-h-THPO-WPRE.

\section{Results}

To develop an immune-humanized ER+ model representing a major unmet medical need in breast cancer, we chose the HCI-013 PDX line, which is a metastatic, endocrine resistant ER+ model of lobular breast cancer [15]. Importantly, this model possesses a naturally- occurring Y537S hotspot mutation in the ligand binding domain of ESR1, which represents one of the two most common
ESR1 mutations in MBC. For immune-humanization experiments, we chose NSG-SGM3 mice, an immunodeficient strain with genes knocked-in to express human stem cell factor (SCF), granulocyte-macrophage colony stimulating factor (GM-CSF) and IL-3 [44]. The expression of these three human cytokines enables improved myeloid immune reconstitution in mice [44-46].

\section{Optimization of estrogen supplementation in $\mathrm{HCl}-013 \mathrm{PDX}$ tumor growth for immune-humanization}

One of the challenges in modeling human ER+ breast cancer in mice is the typical requirement for supplemental estrogen due to low levels of endogenous murine E2 [47, 48]. HCI-013 is an E2-responsive model [49] and, in the presence of exogenous E2, HCI-013 reliably produces tumors in NSG mice, with somewhat heterogeneous growth rates [15]. Since the majority of our ER+ PDX models, including HCI-013, were developed in NSG hosts, we first asked whether the expression of human cytokines in NSG-SGM3 mice altered the growth of HCI-013 PDX tumors. We therefore implanted HCI013 tumors in NSG and NSG-SGM3 mice and tested our standard protocol for estrogen supplementation [15] using a $0.4 \mathrm{mg}$ E2 pellet implanted at the time of surgery, followed by the addition of E2 to the drinking water 4 weeks post tumor inoculation (Fig. 1a). Tumors grew comparably in both mouse strains, usually reaching $1000 \mathrm{~mm}^{3}$ in approximately 7-8 weeks, thus ruling out the effect of human cytokines on tumor growth (Fig. 1b). However, this relatively fast tumor growth would not allow for complete immune reconstitution in NSG-SGM3 mice, which takes a minimum of 9 weeks for myeloid cell development and longer time for $\mathrm{T}$ cell and NK cell development [44, 50-52]. Thus, we next tested several conditions with reduced estrogen doses in NSGSGM3 mice to find a setting in which tumors would grow well, but slowly enough to facilitate the time required for immune system development. For this, we supplemented exogenous estrogen by either implanting half dose $(0.2 \mathrm{mg})$ E2 pellets or giving E2 only in the drinking water (Fig. 1c). We found that both strategies supported a tumor growth rate that gives enough time for immune humanization (Fig. 1d). We decided to move forward with E2 supplementation via drinking water, since it is a non-invasive method and enables estrogen delivery to be stopped at any time by switching back to acidified drinking water.

\section{Effects of supplemental estrogen on immune humanization}

Estrogen can have profound effects on the immune system [53, 54], so we asked whether supplementation of estrogen in the drinking water would affect 


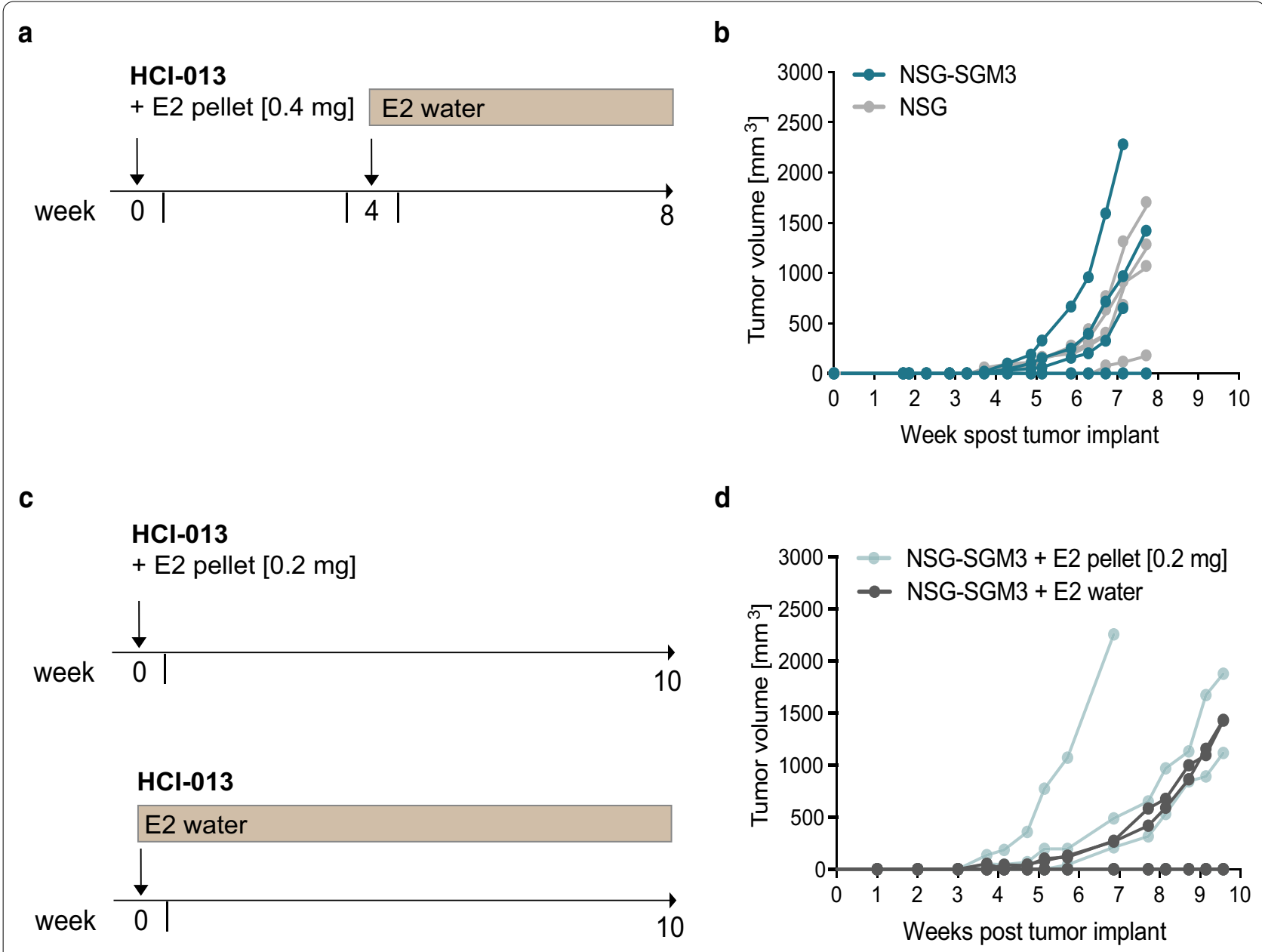

Fig. 1 Optimization of exogenous estrogen supplementation methods to promote $\mathrm{HCl}-013$ tumor growth in experimental mice. a Experimental timeline. 8 weeks old female NSG-SGM3 or NSG mice were inoculated with $\mathrm{HCl}-013$ tumor fragments into the MFP $(n=5)$. On the same day, mice were implanted with $0.4 \mathrm{mg}$ E2 pellets, while 4 weeks post tumor implantation, mice received E2 supplemented acidified drinking water until the end of the experiment. This reflects our standard exogenous estrogen supplementation for ER+ PDX lines [15]. b Tumor growth was monitored until mice were harvested 8 weeks post tumor implantation $(n=5)$. HCl-013 PDX tumors have previously been reported to have heterogeneous growth (DeRose et al. 2011), which we also observed here. c Experimental timeline. 8 weeks old female NSG-SGM3 mice were implanted with $\mathrm{HCl}-013$ tumor fragments into the MFP $(n=5)$. On the same day, mice were either implanted with $0.2 \mathrm{mg}$ E2 pellets, which represents half of the pellet size of our standard protocol (upper timeline), or received E2 supplemented acidified drinking water until the end of the experiment (lower timeline). d Tumor growth was monitored until mice were harvested 10 weeks post tumor implantation $(n=5)$

reconstitution of the human immune system in NSG-SGM3 mice. To test this, we first performed an experiment to humanize NSG-SGM3 mice without implantation of PDX tumors (Fig. 2). For immunehumanization, NSG-SGM3 mice were treated with busulfan to achieve myeloablation as previously described $[55,56]$. We chose this approach over irradiation since the latter might be more prone to cause adverse effects, including the severe anemia reported in irradiated humanized MISTRG and NSG-SGM3 mice $[57,58]$. Mice were then immune-humanized by IV injection of human BM-derived CD34+ HSCs
(Fig. 2a). It has been previously reported that HLAmatching donor HSCs to PDX tumor does not affect tumor growth [33, 59]. However, to minimize chances of an allograft reaction while maximizing chances of immune $\mathrm{T}$ cell tolerance against human PDX tumors, we implanted the tumors one day after IV injection of HSCs, so that newly generated T cells could develop in parallel with a growing tumor. BM-derived immature HSCs were used instead of mature PBMCs to avoid graft-versus-host disease (GvHD) [33]. The acidified drinking water was supplemented with E2 beginning $24 \mathrm{~h}$ post-humanization, which is the time point 
a

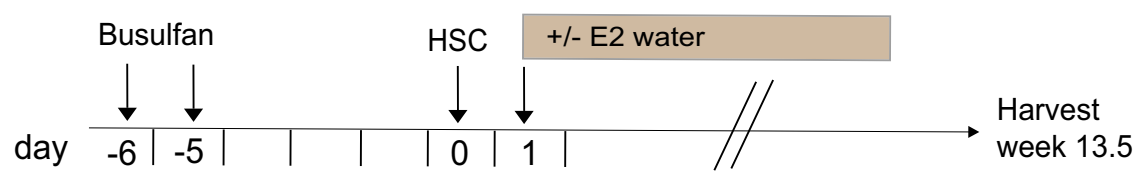

b

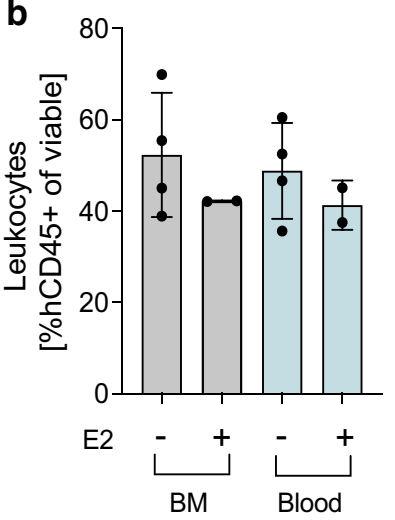

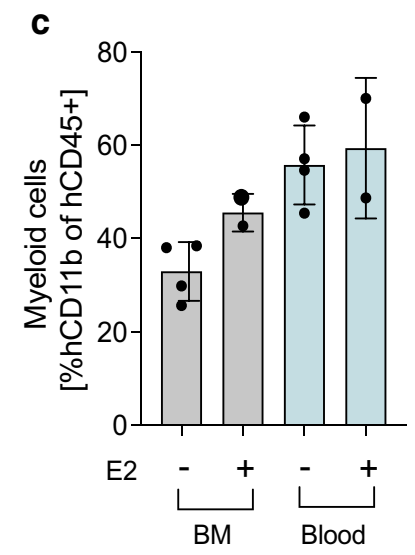
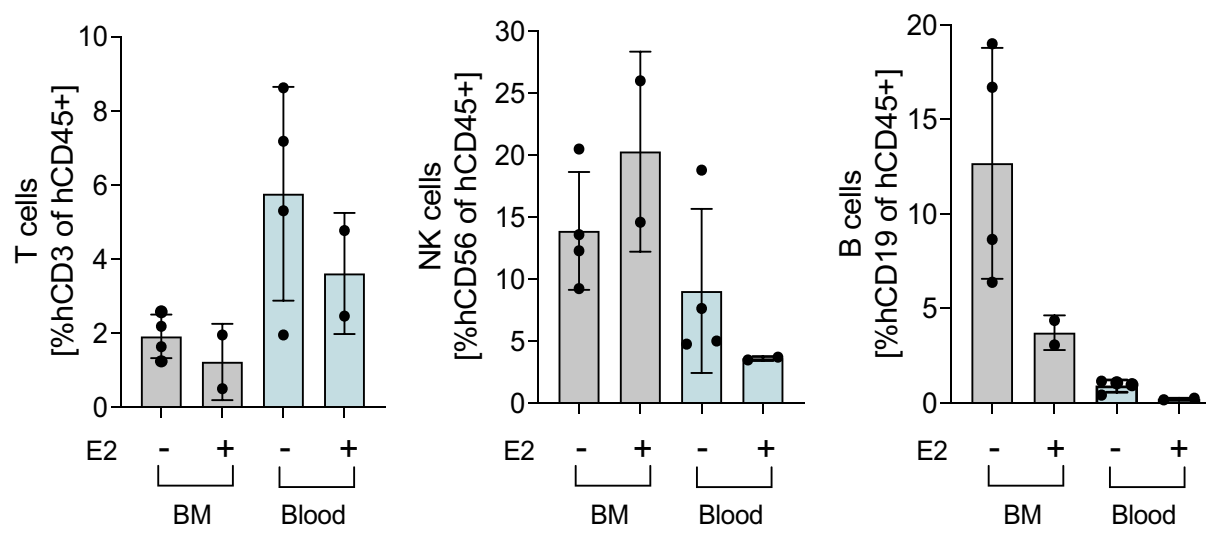

Fig. 2 Effect of E2 supplementation on immune humanization in mice. a Experimental timeline. 6-7 weeks old NSG-SGM3 female mice were injected with $20 \mathrm{mg} / \mathrm{kg} /$ day busulfan on two consecutive days. Five days later, mice were IV injected with 85,000 hCD34 $4^{+} \mathrm{HSCs}$ and $24 \mathrm{~h}$ later received E2 supplemented acidified drinking water for 3.5 weeks ( $n=5$, HSC donor ID 7734, KIR-mismatched to HCI-013). Control mice were kept on unsupplemented acidified drinking water. Mice were harvested 13.5 weeks post-humanization, at which point BM and blood were freshly isolated, and flow staining was performed. Flow cytometry was performed on the day of tissue harvest without fixation. b Flow cytometry analysis of $\mathrm{hCD} 45^{+}$cells in BM, and blood of humanized mice receiving E2 or unsupplemented acidified drinking water are shown as percent of viable cells $(n=2-4)$. c Flow cytometry analysis of $\mathrm{hCD} 1 \mathrm{~b}^{+}, \mathrm{hCD} 3^{+}, \mathrm{hCD} 56^{+}$and $\mathrm{hCD} 19^{+}$cells in BM and blood of humanized mice receiving E2 or unsupplemented acidified drinking water are shown as percent of hCD45 ${ }^{+}$cells $(n=2-4)$

where we planned to implant PDX tumors for future experiments. Compared to the control group, which received acidified drinking water without E2, no differences in humanization were observed in BM or blood based on the percentage of hCD $45+$ cells, which averaged $46.3 \%$ of the mouse blood across all experimental groups (Fig. 2b). As a reference, commercially available humanized mice are considered to be humanized at minimum $\sim 25 \% \mathrm{hCD} 45+$ cells in mouse blood. In addition, no significant effects of E2 on the development of myeloid $(\mathrm{hCD} 11 \mathrm{~b}+)$ cells, $\mathrm{T}(\mathrm{hCD} 3+)$ cells, NK (hCD56+) cells or B (hCD19+) cells were observed, although there was a trend towards development of more myeloid cells, and fewer $\mathrm{B}$ and $\mathrm{T}$ cells in mice receiving E2 (Fig. 2c).
Unfortunately, we noticed that humanized mice exposed to exogenous E2 developed severe anemia after 1.5 weeks of estrogen supplementation, sometimes to the point of sickness that required euthanasia. Thus, we next investigated whether this was a reproducible phenomenon or an underlying donor-specific effect. We repeated the experiment using a different HSC donor and included HCI-013 tumor engraftment with E2 supplementation. After myeloablation, NSG-SGM3 mice were injected with HSCs, followed one day later by orthotopic implantation of HCI-013 PDX tumor tissue and E2 supplementation via drinking water (Fig. 3a). We chose the timing of PDX tumor implantation to be close to the injection of HSCs to avoid potential GvHD or graft-versus-tumor reactions by mature $\mathrm{T}$ cells in already-humanized mice. This way, 
a

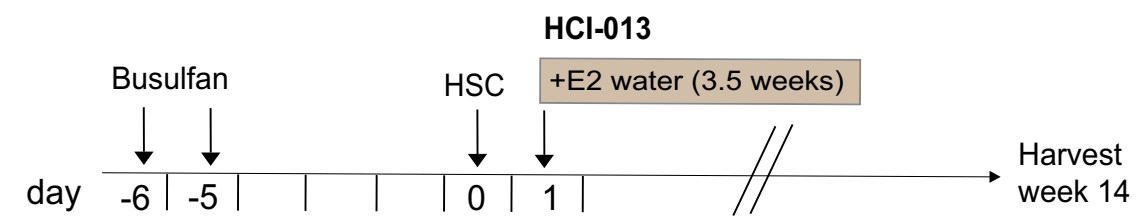

b

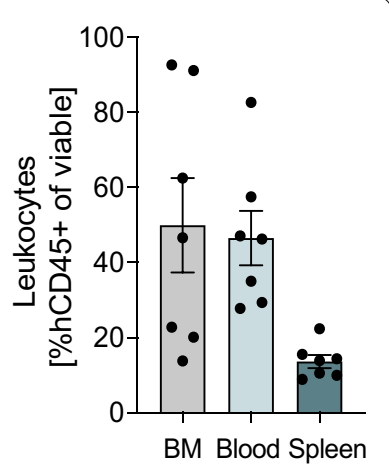

C
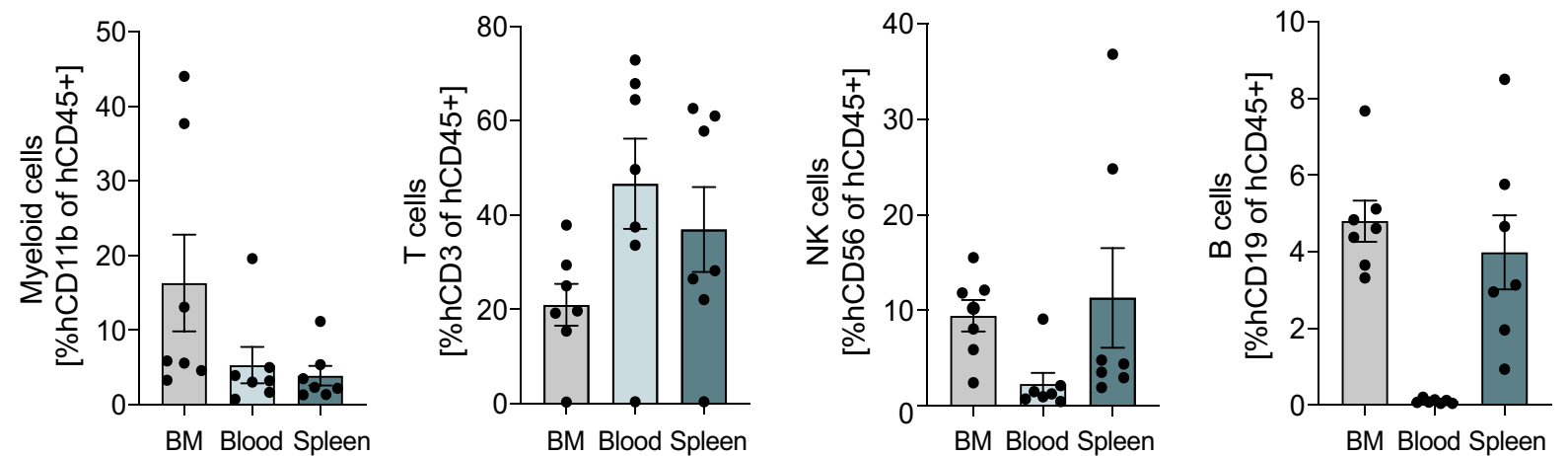

Fig. 3 Exogenous E2 supplementation in immune-humanized mice bearing HCl-013 tumors. a Experimental timeline. 6-7 weeks old female NSG-SGM3 mice were injected with $20 \mathrm{mg} / \mathrm{kg} /$ day busulfan on two consecutive days. Five days later, mice were IV injected with 85,000 hCD34 HSCs and $24 \mathrm{~h}$ later implanted with $\mathrm{HCl}-013$ tumor fragments into the MFP. Animals received E2 supplemented drinking water for 3.5 weeks until the end of the experiment ( $n=10$, HSC donor ID 12241, KIR-matched to HCl-013). Mice were harvested 14 weeks post-humanization. Control tumors were implanted into non-humanized NSG-SGM3 mice $(n=5)$. On the day of harvest, BM, blood and spleens were isolated, and flow staining and flow cytometry were performed on the same day without fixation. $\mathbf{b}$ Flow cytometry analysis of hCD $45^{+}$cells in BM, blood and spleen of humanized mice are shown as percent of viable cells $(n=7)$. $\mathbf{c}$ Flow cytometry analysis of hCD3 ${ }^{+}, \mathrm{hCD} 11 \mathrm{~b}^{+}, \mathrm{hCD} 19^{+}$and hCD56 ${ }^{+}$cells in BM, blood and spleens of humanized mice are shown as percent of $\mathrm{hCD} 45^{+}$cells $(n=7)$. All data shown as mean \pm SEM

T cells develop in tumor-bearing mice in the presence of tumor antigens, thus increasing the probability of $\mathrm{T}$ cell tolerance against human tumor cells. 14 weeks posthumanization, we found effective hCD45+ immune cell reconstitution in BM $(\sim 50 \%)$, blood $(\sim 47 \%)$, and spleen $(\sim 18 \%)$, and we were again able to detect the development of human myeloid cells, T cells, NK cells and B cells in each of these organs (Fig. 3b, c).

However, we again found that immune-humanized mice receiving E2 became severely anemic, thus excluding the possibility of a donor-specific effect given that HSCs were obtained from two different donors for these experiments. While tumors were palpable at the beginning of the experiment (Fig. 3), some mice had to be euthanized due to anemia prior to the planned endpoint. Removal of E2 from the drinking water reversed anemia in surviving mice, allowing the recovery of some animals (Additional file 1: Fig. S5), but tumor growth was not sustained, most likely due to the fact that E2 supplementation had to be stopped. Regarding the onset of anemia, we excluded the possibility of a donor-specific effect given that HSCs obtained from two different donors were used in these experiments. Since anemia also occurred in control mice that did not receive tumor implants, we concluded that anemia was not dependent on the presence of tumor. Instead, it appeared that even low levels of supplemental E2 delivered in drinking water caused severe anemia specifically in immune-humanized mice.

\section{Endogenous mouse estrogen levels are not sufficient for $\mathrm{HCl}-013$ tumor growth}

Although the HCI-013 PDX model was originally developed in mice with exogenous E2 supplementation, we hypothesized that the presence of the Y537S mutation in ESR1 might render the tumor independent of estrogen. We next tested whether HCI-013 could grow in immune-humanized mice without E2 supplementation, 
but with intact ovaries, leaving the PDX tumor exposed to low levels of endogenous murine estrogen. Thus, NSGSGM3 mice with intact ovaries were immune-humanized followed by orthotopic implantation of HCI-013 PDX tumors without supplemental E2 (Fig. 4a). In this experiment, without E2 supplementation, mice did not become anemic, and tissues were collected 18.5 weeks post-humanization for human immune cell characterization. The results revealed typical reconstitution of the human immune system, as indicated by the presence of hCD45+ cells in the BM, blood, and spleen (Fig. 4b), and CD34+ HSCs differentiated into all of the major immune lineages including $\mathrm{T}$ cells, myeloid cells, B cells, and NK cells (Fig. 4c). At this later time point, $\mathrm{T}$ cells were the predominant human immune cells in all analyzed tissues. Unfortunately, though, in the absence of exogenous E2, no tumor growth was observed in either immunehumanized or non-humanized NSG-SGM3 mice. Thus, we concluded that endogenous estrogen levels from murine ovaries were not sufficient to support HCI-013 tumor growth in the time frame of our experiment, despite the presence of the Y537S mutation. This challenge, along with E2-induced anemia in immune-humanized mice, precluded us from successfully developing an immune-humanized PDX model of ER+ breast cancer that depends on supplemental E2.

\section{Development of an estrogen-independent $\mathrm{HCl}-013 \mathrm{PDX}$ model}

After discovering the need to generate an estrogen-independent PDX model of ER+ MBC, we set out to develop a model of $\mathrm{ER}+\mathrm{MBC}$ that does not require E2 supplementation. To achieve this, we transplanted HCI-013 into OVX mice in the absence of exogenous E2 (Fig. 5a). Tumors eventually grew, albeit much more slowly than in mice receiving exogenous E2 [15]. We harvested these

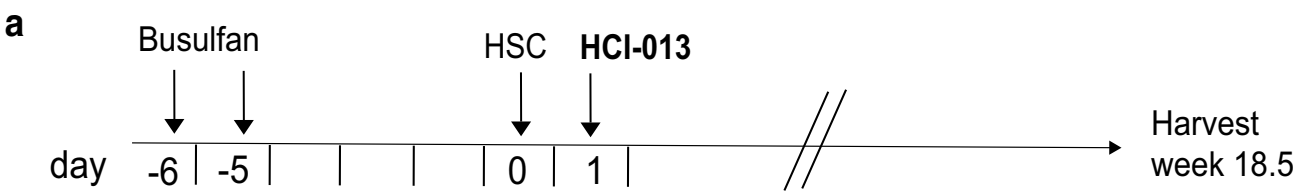

b

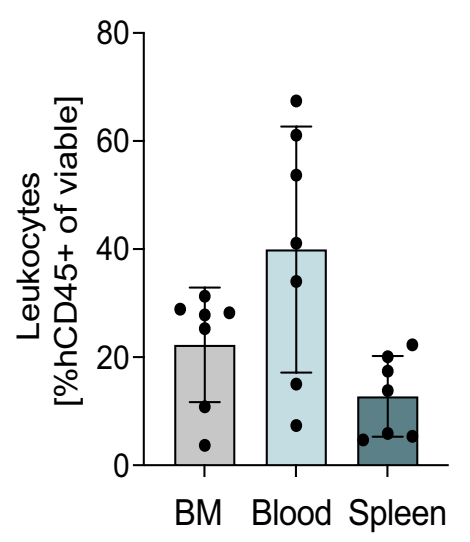

C

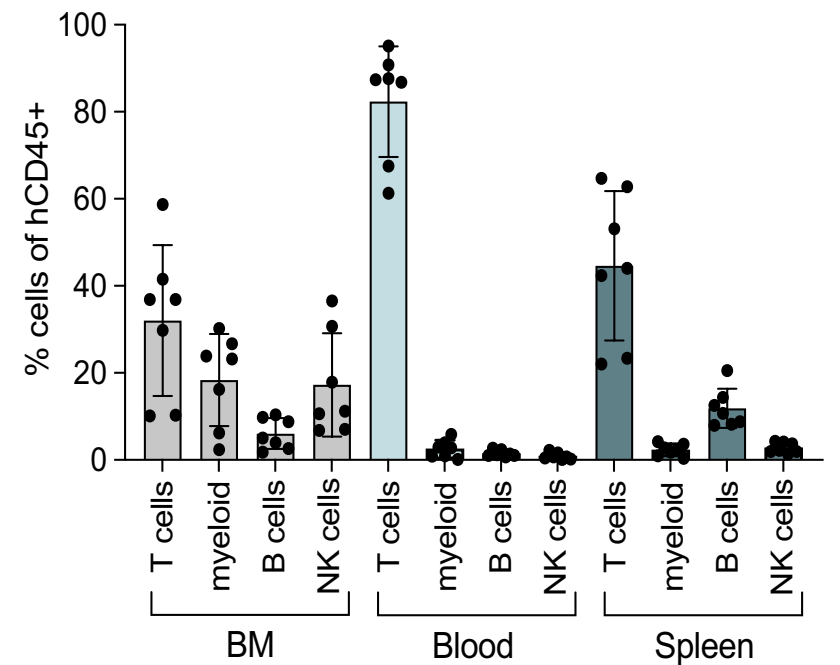

Fig. 4 Immune humanization of mice bearing HCl-013 PDX tumors without exogenous E2. a Experimental timeline. 6-7 weeks old female NSG-SGM3 mice were injected with $20 \mathrm{mg} / \mathrm{kg} /$ day busulfan on two consecutive days. Five days later, mice were IV injected with 85,000 hCD34 $\mathrm{HSCS}$ and $24 \mathrm{~h}$ later implanted with $\mathrm{HCl}-013$ tumor fragments into the MFP. Animals were harvested 18.5 weeks post-humanization $(n=10, \mathrm{HSC}$ donor ID BM4410, KIR-matched to HCl-013). Control tumors were implanted into non-humanized NSG-SGM3 mice $(n=3)$. On the day of harvest, BM, blood and spleens were isolated, and flow staining and flow cytometry were performed on the same day without fixation. $\mathbf{b}$ Flow cytometry analysis of hCD45+ cells in BM, blood and spleen of humanized mice are shown as percent of viable cells $(n=8)$. c Flow cytometry analysis of $\mathrm{hCD}^{+}, \mathrm{hCD} 11 \mathrm{~b}^{+}, \mathrm{hCD} 19^{+}$and $\mathrm{hCD} 56^{+}$cells in BM, blood and spleens of humanized mice are shown as percent of hCD $45^{+}$cells $(n=8)$. All data are shown as mean \pm SEM 
tumors, expanded them for two weeks as primary cultures in charcoal-stripped serum and phenol red-free medium, and then re-implanted them into OVX mice to validate their estrogen independence [15]. The resulting isogenic estrogen-independent HCI-013 PDX line (HCI013EI) retains expression of ER and PR and resembles the morphology of the original line (Fig. 5b). Successful development of an estrogen-independent subline of HCI-013 was consistent with the fact that the patient's tumor was resistant to multiple lines of endocrine therapy, and she unfortunately died from MBC. Interestingly, the allele frequency of the Y537S mutation in HCI-013EI PDX tumors remained similar to parental HCI-013 PDX tumors (Fig. 5c), suggesting that the ability of $\mathrm{HCI}-$ 013EI to grow without exogenous E2 cannot simply be explained by an increase in mutational burden of ESR1.

We validated the endocrine resistant nature of $\mathrm{HCI}$ 013EI by treating with fulvestrant, which is a SERD that can be effective against mutant ER [60]. In parental HCI013 PDX tumors, fulvestrant treatment led to immediate control of tumor growth (stable disease), but did not result in tumor regression (Fig. 5d). On the other hand, HCI-013EI PDX tumors did not initially respond to fulvestrant. Instead, they displayed a delayed response to the drug after 5-6 weeks of treatment. Long-term treatment with fulvestrant (for more than 300 days) was able to control tumor growth, but was insufficient to achieve a complete response in this model. Residual tumors, as expected, had low levels of ER following long-term fulvestrant treatment (Fig. 5e). Altogether, these data indicate that HCI-013EI tumors have reduced dependence on E2, and reflect a scenario of endocrine resistance, thus making it a good model for $\mathrm{ER}+\mathrm{MBCs}$ that are difficult to treat.

\section{Immune-humanization of the estrogen-independent HCl-013EI PDX line}

Next, we immune-humanized the HCI-013EI PDX model using a similar protocol for immune reconstitution as in previous experiments, but without the addition of E2 (Fig. 6a). At the endpoint, which was 12 weeks post-humanization, we again saw effective humanization in BM $(\sim 52 \%)$, blood $(\sim 47 \%)$, and spleen $(\sim 18 \%)$ (Fig. 6b), and confirmed with flow cytometry that myeloid cells, T cells, NK cells and B cells had differentiated in these mice (Fig. 6c). Interestingly, amongst the analyzed subpopulations myeloid cells were the predominant human cell type that developed in immunehumanized HCI-013EI PDXs. HCI-013EI tumors grew similarly in both humanized and non-humanized NSGSGM3 mice, although there were two fast-growing outliers in the humanized group (Fig. 6d). Tumor take rate in humanized mice was $80 \%$ ( $n=8 / 10$ mice), and $60 \%$ in non-humanized mice ( $n=3 / 5$ mice), indicating that the reconstituted human immune cells did not reject PDX tumor growth. Double IHC stains of human-specific cytokeratin proteins (CAM5.2) and the proliferation marker phospho-histone $\mathrm{H} 3$ ( $\mathrm{PHH} 3)$ revealed that the fraction of proliferating tumor cells was similar between non-humanized and humanized mice, averaging $0.7 \%$ of cells in mitosis (Fig. 6e, f). Further analysis of PHH3+ cells revealed that most of the actively proliferating cells were human tumor cells in both humanized and nonhumanized HCI-013EI tumors (Fig. 6g). Interestingly, while it was rare to find cleaved caspase 3 (CC3)-positive cells in non-humanized HCI-013EI tumors, a variable level of CC3 staining was detected in humanized tumors, suggesting that immune-humanization may contribute to apoptosis (Fig. 6f). However, we were able to successfully reconstitute human immune cells in an endocrine-resistant $\mathrm{ER}+$ model of $\mathrm{MBC}$, and immune-humanization did not result in rejection of the PDX tumors.

\section{Characterization of the tumor microenvironment in immune-humanized $\mathrm{HCl}-013 \mathrm{EI}$ PDX mice}

In an attempt to further dissect the nature of the reconstituted intratumoral human immune subpopulations, we characterized the tumor microenvironment of humanized HCI-013EI PDX tumors using IHC and IF techniques (Fig. 7). IHC staining showed ER expression in tumor

(See figure on next page.)

Fig. 5 Development of an estrogen-independent $\mathrm{HCl}-013$ PDX line (HCl-013El). a HCl-013 PDX tumors were grown in mice with intact ovaries and exogenous E2 supplementation ( $0.4 \mathrm{mg}$ E2 pellet, and E2 water starting 4 weeks post tumor implant). At end point, tumors were harvested and re-implanted into OVX mice with cleared fat pads, without E2 supplementation. Once fully grown, tumors were harvested, digested, and tumor cells were expanded in tissue culture for 2 weeks in estrogen deprived conditions (phenol red-free medium, with charcoal stripped serum and without estrogen supplementation). Tumor cells were then re-implanted into OVX mice with cleared fat pads, without E2 supplementation. The estrogen-independent tumors that grew out under these conditions were expanded, validated and named HCl-013El. b Histological comparison of ER, PR, CAM5.2, hCD45, and mouse (ms) CD31 stains in HCl-013 and HCl-013El PDX tumors. c Detection of Y537S homozygous ESR1 mutation in $\mathrm{HCl}-013$ and $\mathrm{HCl}-013 \mathrm{El}$ PDX tumors using droplet digital PCR. Graph shows 2D scatter plots with fluorescent detection of individual droplets with either gDNA or cDNA. Dots represent droplets with WT (green), or mutant ESR1 (blue) genotypes, or droplets containing both WT and mutant ESR1 (orange). Droplets without DNA content are indicated in black. $\mathbf{d}$ Tumor growth curves of $\mathrm{HCl}-013$ and $\mathrm{HCl}-013 \mathrm{El}$ under fulvestrant treatment (200 mg/kg). All data shown as mean \pm SEM. e Histological comparison of ER and CAM5.2 IHCs in HCI-013EI PDX tumors treated with long-term fulvestrant or vehicle 
a

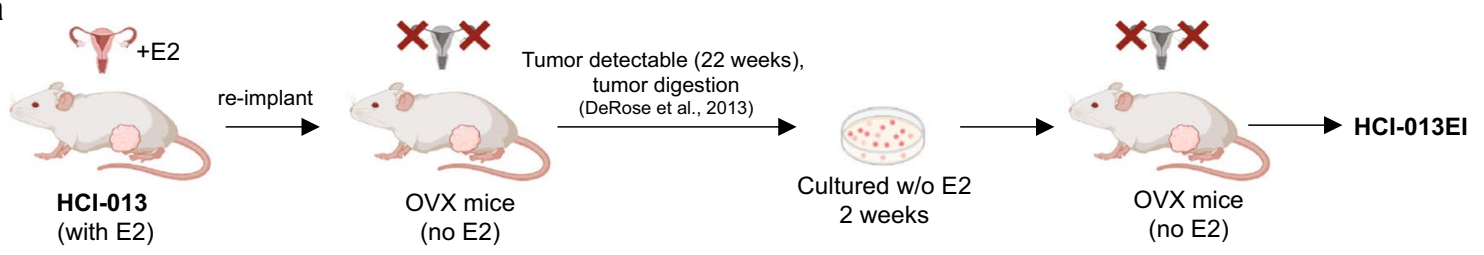

b

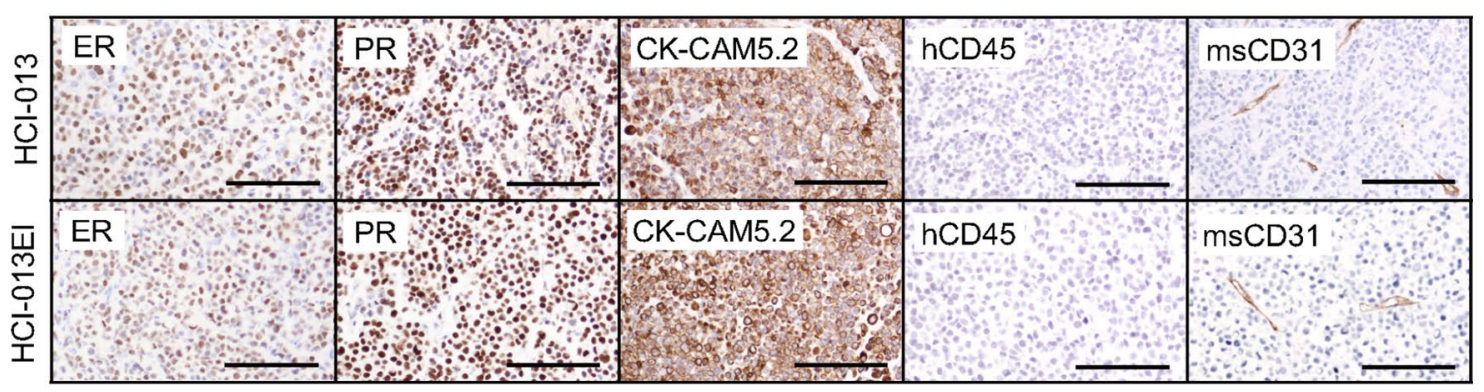

Scale bars $=100 \mu \mathrm{m}$

C
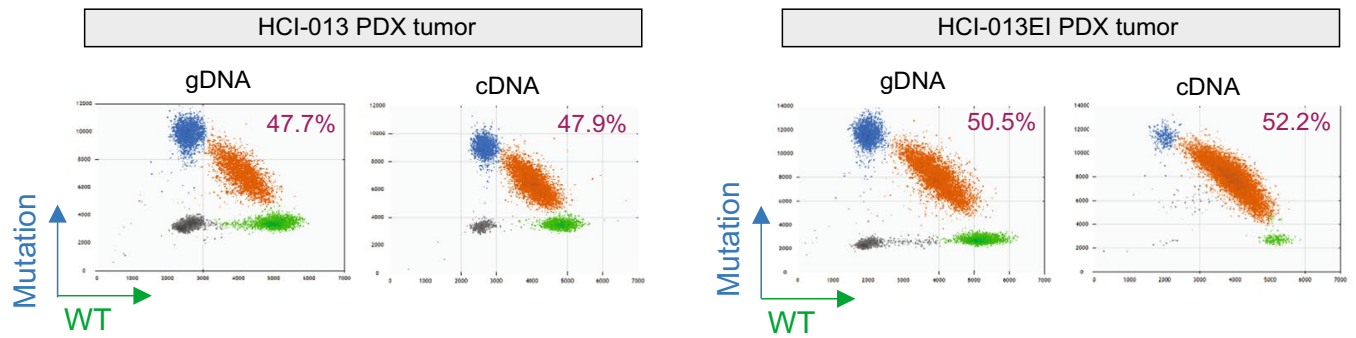

d
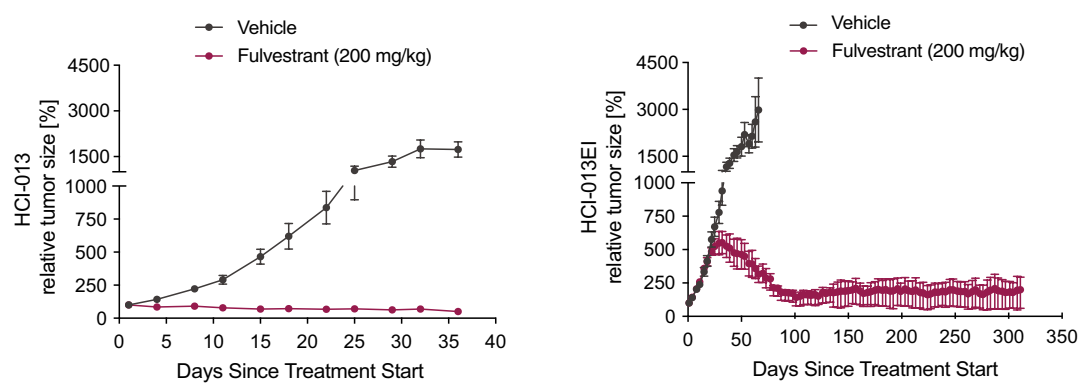

e

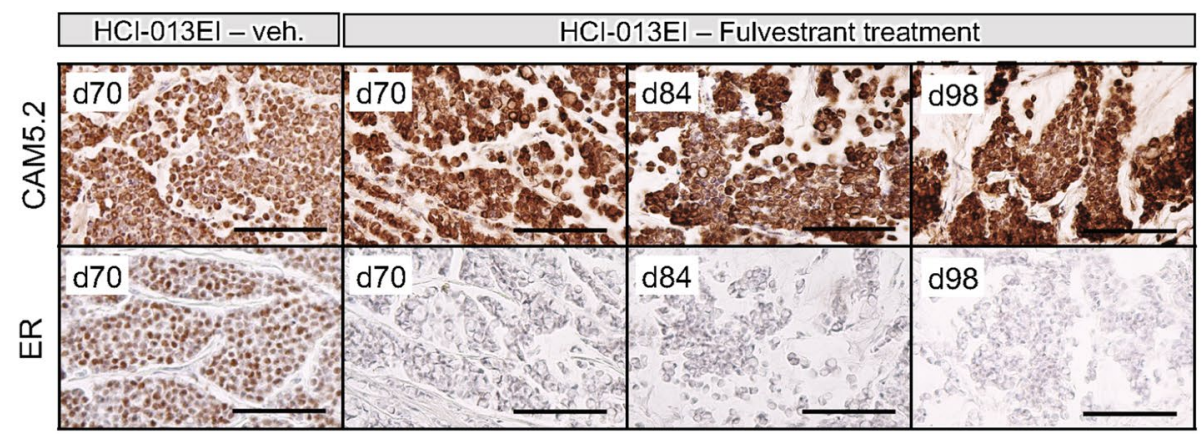

Scale bars $=100 \mu \mathrm{m}$

Fig. 5 (See legend on previous page.) 


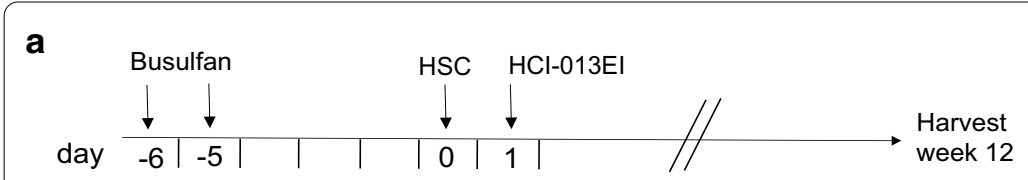

b

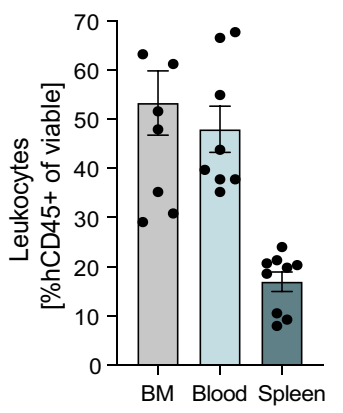

c

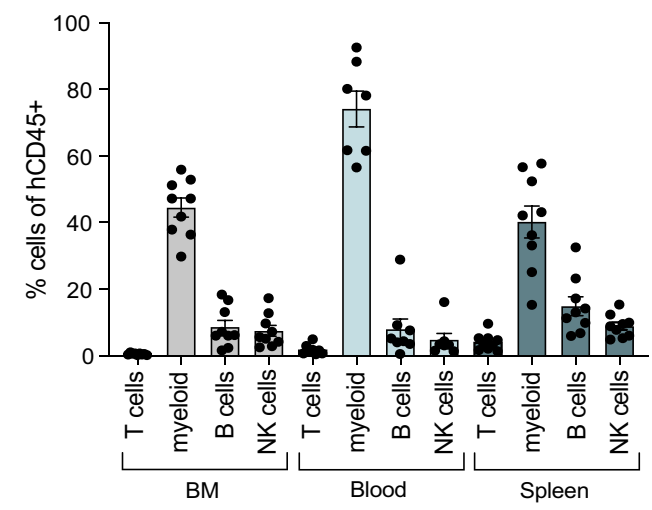

d

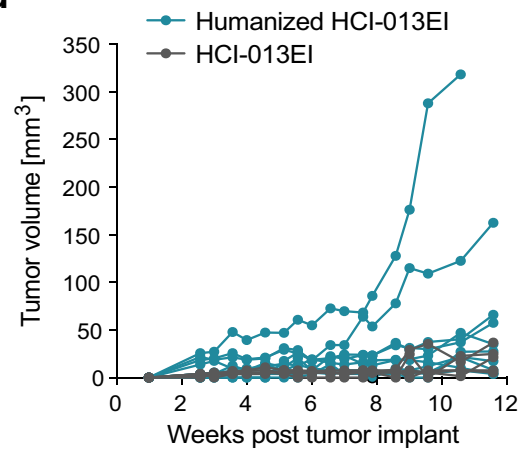

e

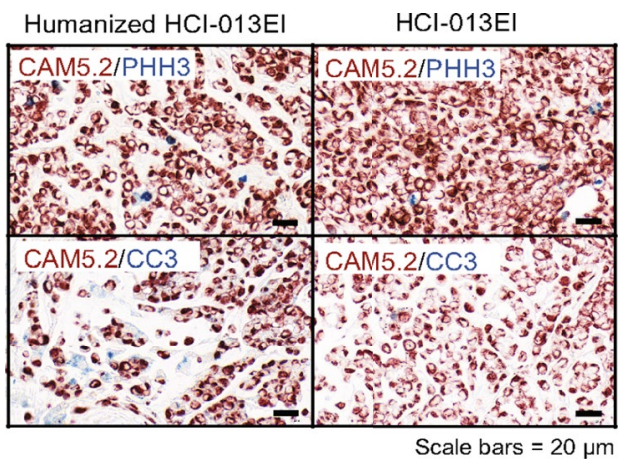

f

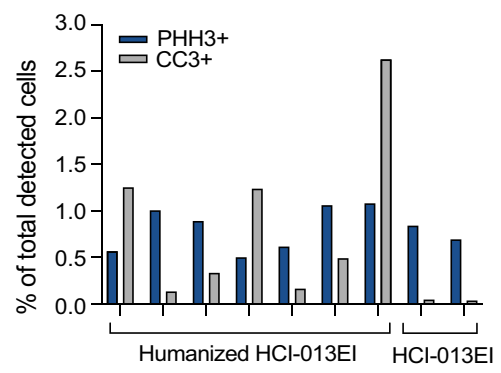

g

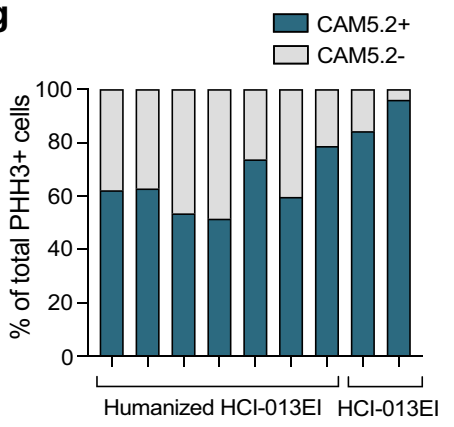

Fig. 6 Immune humanization of mice bearing HCl-013EI PDX tumors. a Experimental timeline. 6-7 weeks old NSG-SGM3 female mice were injected with $20 \mathrm{mg} / \mathrm{kg} /$ day busulfan on two consecutive days. Five days later, mice were IV injected with 85,000 hCD34+ $\mathrm{HSCs}$ and $24 \mathrm{~h}$ later implanted with $\mathrm{HCl}-013 \mathrm{El}$ tumor fragments into the MFP, without exogenous E2 supplementation. Animals were harvested 12 weeks post-humanization ( $n=10$, HSC donor ID 7734, KIR-mismatched to HCl-013). b Flow cytometry of hCD45 ${ }^{+}$cells in BM, blood and spleen of humanized mice are shown as percent of viable cells $(n=9)$. c Flow cytometry of hCD $11 b^{+}, \mathrm{hCD}^{+}, \mathrm{hCD} 56^{+}$and $\mathrm{hCD} 19^{+}$cells in BM, blood and spleens of humanized mice are shown as percent of $\mathrm{hCD} 45^{+}$cells $(n=9)$. $\mathbf{d} \mathrm{HCl}-013 \mathrm{El}$ tumor growth of humanized mice compared to non-humanized control mice (humanized $n=9$, controls, $n=5)$. e Representative images of double IHC stains of HCl-013El PDX tumors from humanized and control mice. Upper panel: CAM5.2 (red) and PHH3 (blue). Lower panel: CAM5.2 (red) and CC3 (blue). f Quantification of e showing PHH3+ or CC3+ cells as percentages of total cells detected in $\mathrm{HCl}-013 \mathrm{El}$ PDX tumors across both groups. $\mathbf{g}$ Quantification of e showing CAM5.2+ and CAM5.2- cells as percentages of all proliferating $\mathrm{PHH} 3+$ cells detected in $\mathrm{HCl}-013 \mathrm{El}$ PDX tumors across both groups. All data shown as mean $\pm \mathrm{SEM}$

cells is maintained in immune-humanized HCI-013EI PDXs (Fig. 7a). We also found that intratumoral blood vessels are of murine origin, similar to non-humanized PDX models [9], as tumors stained negative for hCD31 (data not shown). Whenever present, hCD45+ cells were distributed throughout the tumors (Fig. 7a). However, the degree of human immune cell infiltration varied greatly between animals (Fig. 7b), with some tumors displaying little or no detectable intratumoral human immune cells, despite good systemic immune reconstitution in all mice (Fig. 6b, c). Of note, double IF stains revealed that a large portion of tumor-infiltrating human immune cells are of the myeloid lineage (Fig. 7c, d), in line with myeloid $(\mathrm{hCD} 11 \mathrm{~b}+)$ cells being the predominant reconstituted subpopulation of all hCD45+ cells analyzed at this timepoint (Fig. 6c). Albeit rarely, intratumoral human B cells were also observed in some mice. On the contrary, we did not detect any human T cells or NK cells within HCI-013EI PDX tumors, although these cells were both 
a

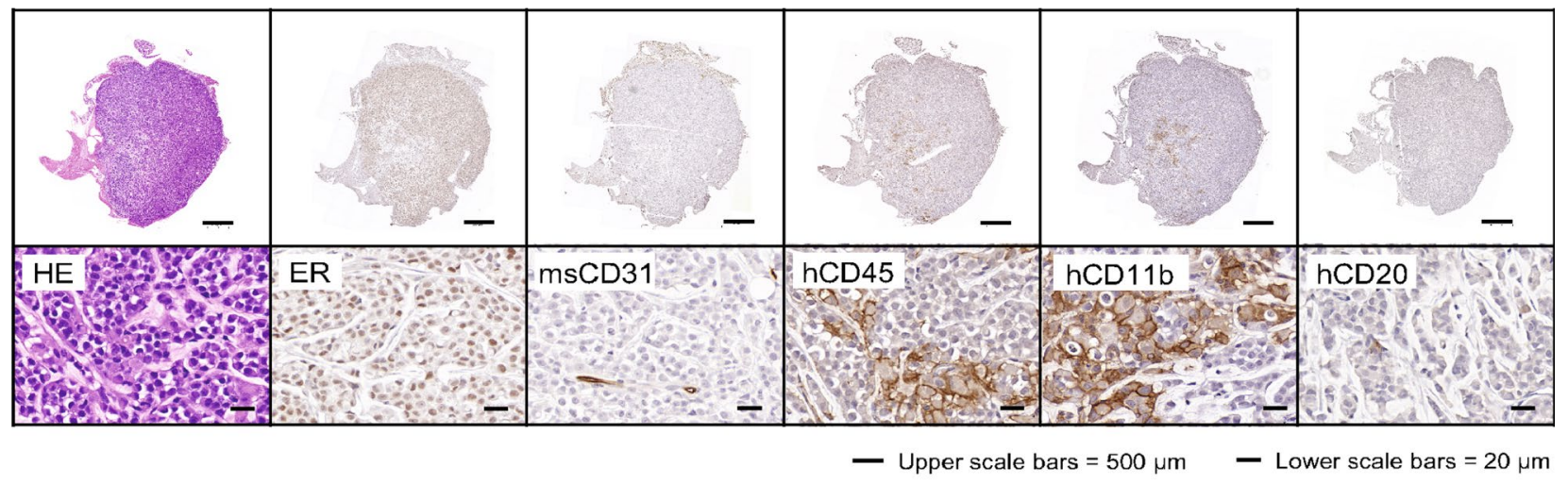

b
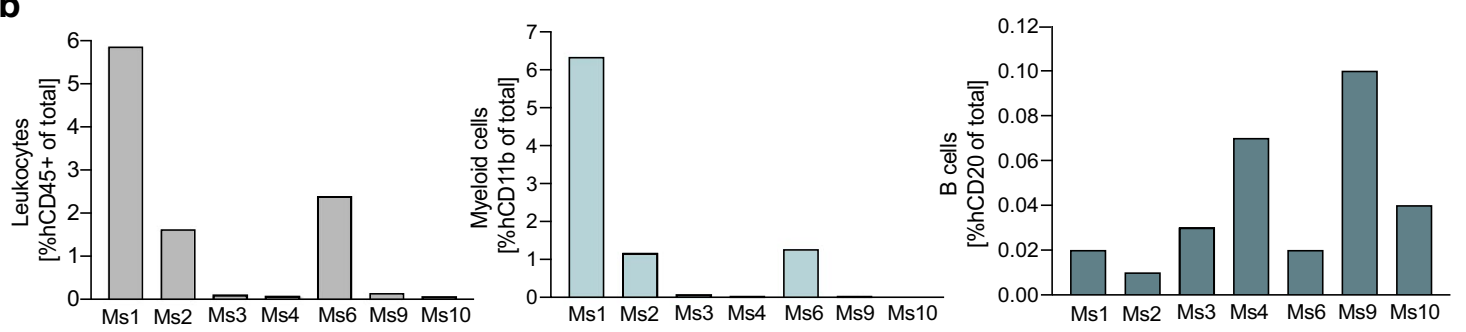

C
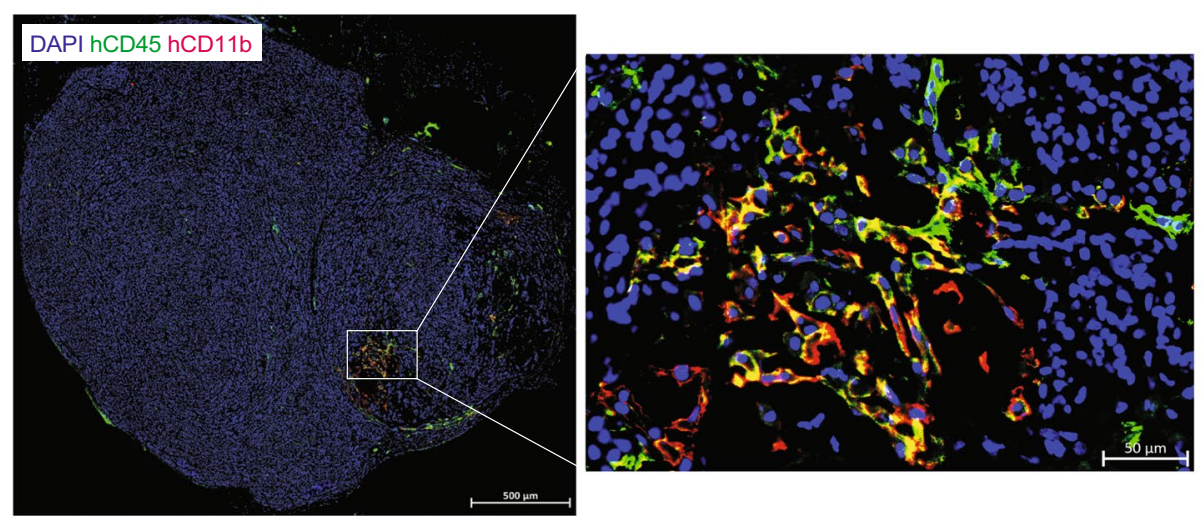

d

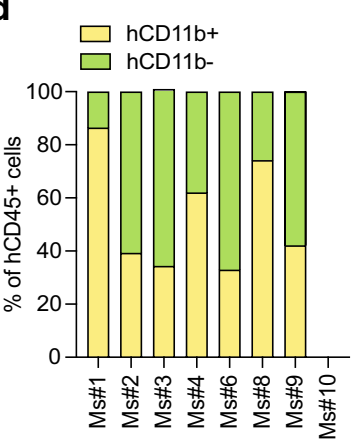

Fig. 7 Tumor microenvironment of immune-humanized HCI-013EI PDX models. a Representative images showing histology of HE, ER, msCD31, hCD45, hCD1 $1 \mathrm{~b}$ and hCD20 stains in immune-humanized HCI-013El PDX tumors from Fig. 6. b Quantification of a of all humanized mice showing intratumoral hCD45 ${ }^{+}$cells (left), hCD11 b+ cells (middle), and hCD20 ${ }^{+}$cells (right) as percentages of total detected cells. c Representative image of double IF staining of the same tumors as in a showing hCD45 (green), and hCD1 1 b + cells (red). d Quantification of e showing hCD11 b+ and hCD $11 \mathrm{~b}$ - cells as percentages of total hCD45+ cells detected in HCl-013El PDX tumors of humanized mice. Note that the presence of tumor-infiltrating human myeloid cells was often found to localize within the core of $\mathrm{HCl}-013 \mathrm{El}$ tumors

reconstituted and each represented $\sim 10 \%$ of the human immune cells detected within the spleen.

\section{Discussion}

We report for the first time the development of an immune-humanized PDX model of endocrine resistant $\mathrm{ER}+\mathrm{MBC}$ that harbors a naturally occurring ESR1 Y537S mutation. Y537S has been shown to be the second most frequently occurring ESR1 mutation in endocrine resistant breast tumors in patients and mutated ESR1 leads to aberrantly increased ER transcriptional activity [5-7]. To date, there are no treatments available that specifically target mutant ER. This is of high relevance since patients whose tumors harbour ESR1 mutations have poor prognosis compared to patients whose tumors are WT ESR1 [8]. Efforts have been made to generate valuable PDX 
models for $\mathrm{ER}^{+} \mathrm{MBC}$, but the need to use immunodeficient hosts to grow PDXs makes it impossible to study the known role of the immune system in tumor progression and treatment response. Hence, we set out to use a novel approach for human immune reconstitution in our model. One of the major differences between our humanization approach and other humanized models is that our tumors are inoculated into mice $24 \mathrm{~h}$ after HSC injection. This enables human immune cells to be exposed to tumor antigens while they are developing in the mouse. Immune-humanization had no negative effect on tumor growth in our study (Fig. 6d), and we did not find a correlation between the degree of immune reconstitution and tumor growth rates, which are naturally heterogeneous in PDX models. We suggest that this strategy might reduce the risk of allogenic $\mathrm{T}$ cell responses, while also avoiding GvHD that could occur if patient-matched mature T cells are used for immune reconstitution.

Characterization of the tumor microenvironment of our immune-humanized model showed a predominant myeloid cell infiltration into tumors. CD11b + myeloid cells are one of the most abundant immune cell component of the human breast tumor microenvironment, where they have been reported to interact with other factors and various tumor cells to foster cancer progression and metastasis $[61,62]$. Specifically, TAMs, myeloidderived suppressor cells and dendritic cells have been shown to play a crucial role in tumor immune evasion by secreting IL-10, IL-12 and arginase-1, leading to suppression of CD8+ T-cell activity and reduced activity of effector $\mathrm{T}$ cells $[63,64]$. Interestingly, the receptor tyrosine kinase RON, which is expressed on resident macrophages, has been recently shown to promote endocrine therapy resistance in ESR1 mutated breast cancers [65]. Thus, since most of the tumor-infiltrating cells are of myeloid origin, our immune-humanized model would be an interesting system to study this mechanism further.

While we do detect human $\mathrm{T}$ cells $(\mathrm{hCD} 3+)$ in peripheral blood and spleens of immune-humanized HCI-013EI PDX mice, T cells were not observed in the tumor microenvironment. Based on data from immune-humanized mice employing the use of HSCs, myeloid cells were shown to develop 8-9 weeks posthumanization, B cells develop after 10-11 weeks, while $\mathrm{T}$ cells develop after 1112 weeks, depending on the model used [66, 67]. Accordingly, in experiments that lasted 14 or 18.5 weeks post-humanization, we detected more $\mathrm{T}$ cells in blood, BM and spleen than we did at 12 weeks post-humanization. Hence, one explanation for our observation could be that at the 12-week timepoint, when we needed to end the experiment with the HCI-013EI model due to tumor burden, $\mathrm{T}$ cells had developed but had not yet started to infiltrate the tumors. Alternatively, since we used NSG-SGM3 mice, which enable optimal myeloid immune reconstitution in mice [44-46], it is possible that the myeloid cells restrict $\mathrm{T}$ cell recruitment into tumors, similar to what is seen in human breast cancers [28]. Yet another possibility for lack of intratumoral $\mathrm{T}$ cells in our model is that HCI-013EI might represent a "cold" tumor. Cold tumors (i.e. noninflamed) are described as solid cancers that have low immune cell infiltration, including low or absent numbers of CD3+ and CD8+ T cells [68-70]. Many breast tumors are considered to be immune "cold" [38], and this is one of the reasons why immune checkpoint blockade is not very effective against this disease [71]. In the case of HCI-013, it is impossible to know whether the original patient tumor was of the immune "cold" nature because no primary tumor material is available; the model was generated from a metastatic pleural effusion fluid sample.

Multiple efforts have been made to find ways to manipulate and improve the infiltration of $\mathrm{T}$ cells into the tumor. In one of these recent studies, vitamin $\mathrm{D}$ was shown to increase intratumoral $\mathrm{T}$ cells in a breast cancer model [72]. In another study in melanoma patients, injection of oncolytic viruses led to an increase in CD8+ $\mathrm{T}$ cell tumor infiltration, thereby promoting the efficacy of anti-PD1 immunotherapy [73, 74]. One possible application for the model we describe here would be to test novel strategies to increase $\mathrm{T}$ cell infiltration into the tumors as a way to increase susceptibility to immunotherapy for breast cancer.

The variable effects of immune-humanization in experimental mice that can be attributed to different HSC donors has been discussed at length, and various studies reported that the extent of humanization, as well as the development of individual immune subtypes, can vary from donor to donor [75, 76]. Using different HSC donors, we found similar trends in the timing of human immune cell development, with myeloid cells being the predominant immune cells detected at earlier timepoints post-humanization, while $\mathrm{T}$ cells developing at later stages. We also found that E2-induced anemia of immune-humanized mice was consistent across multiple HSC donors. Indeed, the veterinary literature contains several reports of estrogen-mediated BM depression followed by severe anemia in other species including dogs and ferrets $[77,78]$. This phenomenon underscores a barrier to the development of immune-humanized models of E2-dependent cancers.

Lastly, the time required for the differentiation of various immune subsets differs and also depends on cytokine signaling. NSG-SGM3 mice are engineered to provide 
human cytokines needed for myeloid development, but the complex milieu of cytokines and other factors necessary for the development of a complete immune system is still lacking. As proof-of-concept, we noted that we could significantly alter immune cell differentiation by delivering additional exogenous cytokines. Using AAVs as vectors to deliver human TPO, IL-7 and IL-15 to NSG-SGM3 mice in our studies, we found that we could strongly skew immune development towards NK cells at the expense of other cell types (Additional file 1: Fig S6a-f). The addition of cytokines or AAVs did not affect tumor size in two different experiments, and we did not find an effect of matching killer immunoglobulin-like receptors (KIR) between HSC donors and the tumor (Additional file 1: Fig. S6g). This study emphasizes the importance of how a balanced supply of human immune cytokines may be tailored to influence development of immune cell types of interest. Future work will be required to fine-tune physiologically-relevant levels of various cytokines and recapitulate the different immune subtypes that dominate in breast cancer [38].

\section{Conclusion}

Modelling ER+ breast cancer in mice is particularly challenging $[47,48]$. While imperfect, we were able to generate an immune-humanized PDX model of ER+ ESR1-mutant endocrine-resistant MBC. Given the lack of therapeutic options that these patients face, we hope that our system might provide a model in which to investigate the function of the immune system in the tumor microenvironment of putatively "immune-cold" ER+ breast cancers.

\footnotetext{
Abbreviations

AAV: Adeno-associated virus; ACD: Acid-citrate-dextrose; BM: Bone marrow; CAM5.2: Human-specific cytokeratin; CC3: Cleaved caspase 3; ddPCR: Droplet digital PCR; DMEM/F12: Dulbecco's Modified Eagle Medium/Nutrient Mixture F-12; DMSO: Dimethyl sulfoxide; E2: Estradiol; El: Estrogen-independent; ER: Estrogen receptor; ESR1: Estrogen receptor 1; FACS: Fluorescence-activated cell sorting; FBS: Fetal bovine serum; FCR: Fc receptor; FFPE: Formalin-fixed paraffin-embedded; FMO: Fluorescence minus one; gDNA: Genomic DNA; GM-CSF: Granulocyte-macrophage colony-stimulating factor; GvHD: Graftvs-host disease; H: Human; HBEC: Human bronchial epithelial cells; HBSS: Hanks' balanced salt solution; HE: Hematoxylin/eosin; HER2: Human epidermal growth factor receptor 2; HRP: Horseradish peroxidase; HSC: Hematopoietic stem cell; IF: Immunofluorescense; IHC: Immunohistochemistry; IL-3/7/10/12/15: Interleukin-3/5/10/12/15; IV: Intravenously; KIR: Killer lg-like receptors; MBC: Metastatic breast cancer; MFP: Mammary fat pad; MISTRG: Mouse strain C;129S4-Rag2tm1.1 Flv Csf1 tm1 (CSF1)Flv Csf2/II3tm1.1 (CSF2,IL3) Flv Thpotm 1.1(TPO)Flv II2rgtm1.1 Flv Tg(SIRPA)1 Flv/J; Ms: Mouse; NBF: Neutral buffered formalin; NK cell: Natural killer cell; NSG-SGM3: Mouse strain NOD.CgPrkdcscid II2rgtm1Wjl Tg(CMV-IL3,CSF2,KITLG)1Eav/MloySzJ; NSG: Mouse strain NOD.Cg-Prkdcscid II2rgtm 1Wj//SzJ; OVX: Ovariectomized; PARP: Poly (ADPribose) polymeras; PBMC: Peripheral blood mononuclear cell; PBS: Phosphatebuffered saline; PDX: Patient-derived xenograft; PHH3: Phospho-histone H3; PR: Progesterone receptor; RBC: Red blood cell; ROI: Region of interest; SCF: Stem cell factor; SEM: Standard error mean; SERD: Selective estrogen receptor degrader; TAM: Tumor-associated macrophage; TNBC: Triple negative breast cancer; TPO: Thrombopoietin; WT:Wildtype.
}

\section{Supplementary Information}

The online version contains supplementary material available at https://doi. org/10.1186/s13058-021-01476-X.

Additional file 1. Fig. S1: Estrogen plasma concentrations in NSG or NSG-SGM3 mice bearing HCl-013 PDX tumors receiving either E2 supplemented acidified drinking water (magenta) or implanted with 0.2 mg estrogen pellets (green) $(n=5$, see experimental timeline in Fig. 1). Data is normalized to E2 plasma levels of non-tumor bearing NSG mice without exogenous E2 supplementation. Fig. S2: Flow cytometry gating strategy for hCD45 as percentage of (a) viable cells and (b) human immune subsets. All gates were set based on FMO controls. Fig. S3: List of antibodies used for IHC and IF stains. Fig. S4: Quantification workflow of $\mathrm{IHC}$ and IF images using QuPath. Fig. S5: Weight comparison of estrogen supplemented immune-humanized and non-humanized HCI-013 PDX mice of experiment shown in Fig. 3. All weights are shown relative to the starting weight of each mouse. Fig. S6: Utilizing a AAV cocktail as a cytokine delivery system to boost NK cell development. (a) Experimental timeline. AAV-hTPO, AAV-hIL15, AAV-hIL7 were IV injected 4 days prior to HSC implantation. (b-f) Flow cytometry of hCD45 as percentage of (b) viable cells and (c-f) human immune subsets. Injection of AAVs results in reduced human myeloid development (c) but significant increase of human NK cell development (d; n=2-5). (g) Tumor weights at the experimental endpoint for two independent experiments with KIR-matched (left) or KIR-unmatched HSCs (right) ( $n=2-7)$. Tumors in humanized mice treated with AAV-cytokines didn't grow significantly different from control groups.(PDF $1049 \mathrm{~kb})$

\section{Acknowledgements}

We would like to thank the University of Utah Office of Comparative Medicine for animal care. We also want to thank Andrew J. Butterfield, Shanna Kuhn, other members of the Welm Lab, and the Huntsman Cancer Institute Preclinical Research Resource for assistance in harvesting and processing organs, and flow cytometry. This work was supported by the DOD Breast Cancer Research Program Era of Hope Expansion award W81XWH-12-1-0077 (to ALW), NCI R01CA221303 (SO), as well as pilot funds from the Utah Center for Clinical and Translational Science, funded by the National Center for Advancing Translational Sciences of the National Institutes of Health under Award Number UL1TR002538. SERD experiments were sponsored by Zentalis Pharmaceutical, Inc. The content is solely the responsibility of the authors and does not necessarily represent the official views of the National Institutes of Health. The University of Utah Flow Cytometry Facility is supported in part by 5P30CA042014-24 from the National Cancer Institute.

\section{Authors' contributions}

SDS: conception, design of the work, data acquisition, data analysis, data interpretation, manuscript writing; AIR: data acquisition, data analysis, data interpretation, manuscript writing; $\mathrm{FH}$ : data acquisition, animal maintenance and care; YSD: data acquisition, animal maintenance and care; AE: conception, data interpretation; MF: data acquisition, animal maintenance and care; JT: animal maintenance and care; LZ: data acquisition, data analysis; ZL: data acquisition, data analysis, data interpretation; SÖ: data interpretation; AAS: funding source, advice on SERD experiments; ALW: conception, funding sources, design of the work, data analysis, data interpretation, manuscript writing. All authors read and approved the final manuscript.

Funding

W81XWH-12-1-0077; UL1TR002538; 5P30CA042014-24; Zentalis Pharmaceuticals, Inc.

\section{Availability of data and materials}

All data generated or analysed during this study are included in this published article [and its supplementary information files].

\section{Declarations}

Ethics approval and consent to participate

Not applicable. 


\section{Consent for publication \\ Not applicable.}

\section{Competing interests}

ALW, SDS, YSD, or MF may receive financial compensation from tangible property licenses managed by the University of Utah if PDX models that they developed are licensed by a for-profit company. ALW received funding from Zentalis Pharmaceuticals, Inc. for a portion of this study. AAS is an employee of Zentalis Pharmaceuticals, Inc.

\section{Author details}

'Department of Oncological Sciences, University of Utah, 2000 Circle of Hope, Salt Lake City, UT 84112, USA. ${ }^{2}$ Huntsman Cancer Institute, University of Utah, 2000 Circle of Hope, Salt Lake City, UT 84112, USA. ${ }^{3}$ Department of Pharmacology and Chemical Biology, UPMC Hillman Cancer Center, Magee Women's Research Institute, University of Pittsburgh, 204 Craft Avenue, Pittsburgh, PA 15213, USA. ${ }^{4}$ Zentalis Pharmaceuticals, Inc., 10835 Road to the Cure, Suite 205, San Diego, CA 92121, USA.

Received: 27 May 2021 Accepted: 11 October 2021 Published online: 30 October 2021

\section{References}

1. Siegel RL, Miller KD, Fuchs HE, Jemal A. Cancer statistics, 2021. CA A Cancer J Clin. 2021;71:7-33.

2. Harris L, Fritsche H, Mennel R, Norton L, Ravdin P, Taube S, et al. American Society of Clinical Oncology 2007 update of recommendations for the use of tumor markers in breast cancer. JCO. 2007;25:5287-312.

3. American Cancer Society. Cancer Facts \& Figures 2021 [Internet]. 2021. https://www.cancer.org/content/dam/cancer-org/research/cancer-factsand-statistics/annual-cancer-facts-and-figures/2021/cancer-facts-andfigures-2021.pdf

4. Rozeboom B, Dey N, De P. ER+ metastatic breast cancer: past, present, and a prescription for an apoptosis-targeted future. Am J Cancer Res. 2019:9:2821-31.

5. Harrod A, Fulton J, Nguyen VTM, Periyasamy M, Ramos-Garcia L, Lai C-F, et al. Genomic modelling of the ESR1 Y537S mutation for evaluating function and new therapeutic approaches for metastatic breast cancer. Oncogene. 2017;36:2286-96.

6. Jeselsohn R, Bergholz JS, Pun M, Cornwell M, Liu W, Nardone A, et al. Allele-specific chromatin recruitment and therapeutic vulnerabilities of ESR1 activating mutations. Cancer Cell. 2018:33:173-186.e5.

7. Fanning SW, Mayne CG, Dharmarajan V, Carlson KE, Martin TA, Novick SJ, et al. Estrogen receptor alpha somatic mutations Y537S and D538G confer breast cancer endocrine resistance by stabilizing the activating function-2 binding conformation. eLife. 2016;5:e12792.

8. Li Z, Wu Y, Bahreini A, Priedigkeit NM, Ding K, Sartorius CA, et al. ESR1 mutant breast cancers show elevated basal cytokeratins and immune activation. Cancer Biol. 2020. https://doi.org/10.1101/2020.12.29.424777.

9. Arnesen S, Blanchard Z, Williams MM, Berrett KC, Li Z, Oesterreich S, et al. Estrogen receptor alpha mutations in breast cancer cells cause gene expression changes through constant activity and secondary effects. Cancer Res. 2021:81:539-51.

10. Zhang QX, Borg A, Wolf DM, Oesterreich S, Fuqua SA. An estrogen receptor mutant with strong hormone-independent activity from a metastatic breast cancer. Cancer Res. 1997;57:1244-9.

11. Finlay-Schultz J, Jacobsen BM, Riley D, Paul KV, Turner S, Ferreira-Gonzalez $A$, et al. New generation breast cancer cell lines developed from patientderived xenografts. Breast Cancer Res. 2020;22:68.

12. DeRose YS, Wang G, Lin Y-C, Bernard PS, Buys SS, Ebbert MTW, et al. Tumor grafts derived from women with breast cancer authentically reflect tumor pathology, growth, metastasis and disease outcomes. Nat Med. 2011;17:1514-20.

13. Matthews SB, Sartorius CA. Steroid hormone receptor positive breast cancer patient-derived xenografts. HORM CANC. 2017;8:4-15.

14. Dobrolecki LE, Airhart SD, Alferez DG, Aparicio S, Behbod F, Bentires-Alj M, et al. Patient-derived xenograft (PDX) models in basic and translational breast cancer research. Cancer Metastasis Rev. 2016:35:547-73.
15. Guillen KP, Fujita M, Butterfield AJ, Scherer SD, Bailey MH, Chu Z, et al. A breast cancer patient-derived xenograft and organoid platform for drug discovery and precision oncology. Cancer Biol. 2021. https://doi.org/10. 1101/2021.02.28.433268.

16. Woo XY, PDXNET Consortium, EurOPDX Consortium, Giordano J, Srivastava A, Zhao Z-M, et al. Conservation of copy number profiles during engraftment and passaging of patient-derived cancer xenografts. Nat Genet. 2021;53:86-99.

17. Byrne AT, Alférez DG, Amant F, Annibali D, Arribas J, Biankin AV, et al. Interrogating open issues in cancer precision medicine with patient-derived xenografts. Nat Rev Cancer. 2017;17:254-68.

18. Zhang X, Claerhout S, Prat A, Dobrolecki LE, Petrovic I, Lai Q, et al. A renewable tissue resource of phenotypically stable, biologically and ethnically diverse, patient-derived human breast cancer xenograft models. Cancer Res. 2013;73:4885-97.

19. Eirew P, Steif A, Khattra J, Ha G, Yap D, Farahani H, et al. Dynamics of genomic clones in breast cancer patient xenografts at single-cell resolution. Nature. 2015;518:422-6.

20. Quail DF, Joyce JA. Microenvironmental regulation of tumor progression and metastasis. Nat Med. 2013;19:1423-37.

21. Giraldo NA, Sanchez-Salas R, Peske JD, Vano Y, Becht E, Petitprez F, et al. The clinical role of the TME in solid cancer. Br J Cancer. 2019:120:45-53.

22. Peinado $H$, Zhang $H$, Matei IR, Costa-Silva B, Hoshino A, Rodrigues $G$, et al. Pre-metastatic niches: organ-specific homes for metastases. Nat Rev Cancer. 2017:17:302-17

23. Labani-Motlagh A, Ashja-Mahdavi M, Loskog A. The tumor microenvironment: a milieu hindering and obstructing antitumor immune responses. Front Immunol. 2020;11:940

24. Mehta AK, Cheney EM, Hartl CA, Pantelidou C, Oliwa M, Castrillon JA, et al. Targeting immunosuppressive macrophages overcomes PARP inhibitor resistance in BRCA1-associated triple-negative breast cancer. Nat Cancer. 2021;2:66-82.

25. Panni RZ, Linehan DC, DeNardo DG. Tumor-infiltrating macrophages, cancer stem cells and therapeutic responses. Oncotarget. 2012;3:1497-8.

26. Neophytou CM, Pierides C, Christodoulou M-I, Costeas P, Kyriakou T-C, Papageorgis $\mathrm{P}$. The role of tumor-associated myeloid cells in modulating cancer therapy. Front Oncol. 2020;10:899.

27. Gatti-Mays ME, Balko JM, Gameiro SR, Bear HD, Prabhakaran S, Fukui J et al. If we build it they will come: targeting the immune response to breast cancer. npj Breast Cancer. 2019;5:37.

28. DeNardo DG, Andreu P, Coussens LM. Interactions between lymphocytes and myeloid cells regulate pro- versus anti-tumor immunity. Cancer Metastasis Rev. 2010;29:309-16.

29. Cannarile MA, Weisser $M$, Jacob W, Jegg A-M, Ries CH, Rüttinger D. Colony-stimulating factor 1 receptor (CSF1R) inhibitors in cancer therapy. J Immunother Cancer. 2017:5:53.

30. Sica A, Larghi P, Mancino A, Rubino L, Porta C, Totaro MG, et al. Macrophage polarization in tumour progression. Semin Cancer Biol. 2008:18:349-55.

31. Hammerl D, Smid M, Timmermans AM, Sleijfer S, Martens JWM, Debets R. Breast cancer genomics and immuno-oncological markers to guide immune therapies. Semin Cancer Biol. 2018;52:178-88.

32. Castellaro AM, Rodriguez-Baili MC, Di Tada CE, Gil GA. Tumor-associated macrophages induce endocrine therapy resistance in $E R+$ breast cancer cells. Cancers. 2019:11:189.

33. Stripecke R, Münz C, Schuringa JJ, Bissig K, Soper B, Meeham T, et al. Innovations, challenges, and minimal information for standardization of humanized mice. EMBO Mol Med. 2020;12(7):e8662.

34. Wang M, Yao L, Cheng M, Cai D, Martinek J, Pan C, et al. Humanized mice in studying efficacy and mechanisms of PD-1-targeted cancer immunotherapy. FASEB J. 2018;32:1537-49.

35. Rios-Doria J, Stevens C, Maddage C, Lasky K, Koblish HK. Characterization of human cancer xenografts in humanized mice. J Immunother Cancer. 2020;8:e000416.

36. Capasso A, Lang J, Pitts TM, Jordan KR, Lieu CH, Davis SL, et al. Characterization of immune responses to anti-PD-1 mono and combination immunotherapy in hematopoietic humanized mice implanted with tumor xenografts. J Immunother Cancer. 2019;7:37.

37. Rosato RR, Dávila-González D, Choi DS, Qian W, Chen W, Kozielski AJ, et al. Evaluation of anti-PD-1-based therapy against triple-negative breast 
cancer patient-derived xenograft tumors engrafted in humanized mouse models. Breast Cancer Res. 2018;20:108.

38. Thorsson V, Gibbs DL, Brown SD, Wolf D, Bortone DS, Ou Yang T-H, et al. The immune landscape of cancer. Immunity. 2018;48:812-830.e14.

39. Duran-Struuck R, Dysko RC. Principles of bone marrow transplantation (BMT): providing optimal veterinary and husbandry care to irradiated mice in BMT studies. J Am Assoc Lab Anim Sci. 2009;48:11-22.

40. DeRose YS, Gligorich KM, Wang G, Georgelas A, Bowman P, Courdy SJ, et al. Patient-derived models of human breast cancer: protocols for in vitro and in vivo applications in tumor biology and translational medicine. Curr Protoc Pharmacol. 2013;Chapter 14:Unit14.23.

41. Amend SR, Valkenburg KC, Pienta KJ. Murine hind limb long bone dissection and bone marrow isolation. J Vis Exp. 2016;6:66.

42. Bankhead P, Loughrey MB, Fernández JA, Dombrowski Y, McArt DG, Dunne PD, et al. QuPath: open source software for digital pathology image analysis. Sci Rep. 2017;7:16878.

43. Wang P, Bahreini A, Gyanchandani R, Lucas PC, Hartmaier RJ, Watters RJ, et al. Sensitive detection of mono- and polyclonal ESR1 mutations in primary tumors, metastatic lesions, and cell-free DNA of breast cancer patients. Clin Cancer Res. 2016;22:1130-7.

44. Billerbeck E, Barry WT, Mu K, Dorner M, Rice CM, Ploss A. Development of human CD4+FoxP3+ regulatory T cells in human stem cell factor-, granulocyte-macrophage colony-stimulating factor-, and interleukin-3-expressing NOD-SCID IL2Rynull humanized mice. Blood. 2011;117:3076-86.

45. Nicolini FE, Cashman JD, Hogge DE, Humphries RK, Eaves CJ. NOD/SCID mice engineered to express human IL-3, GM-CSF and steel factor constitutively mobilize engrafted human progenitors and compromise human stem cell regeneration. Leukemia. 2004;18:341-7.

46. Shultz LD, Brehm MA, Garcia-Martinez JV, Greiner DL. Humanized mice for immune system investigation: progress, promise and challenges. Nat Rev Immunol. 2012;12:786-98.

47. Chatzistamou I, Kiaris H. Modeling estrogen receptor-positive breast cancers in mice: Is it the best we can do? Endocr Relat Cancer. 2016;23:C9-12.

48. Özdemir BC, Sflomos G, Brisken C. The challenges of modeling hormone receptor-positive breast cancer in mice. Endocr Relat Cancer. 2018;25:R319-30.

49. Sikora MJ, Cooper KL, Bahreini A, Luthra S, Wang G, Chandran UR, et al. Invasive lobular carcinoma cell lines are characterized by unique estrogen-mediated gene expression patterns and altered tamoxifen response. Cancer Res. 2014;74:1463-74.

50. Maser I-P, Hoves S, Bayer C, Heidkamp G, Nimmerjahn F, Eckmann J, et al. The tumor milieu promotes functional human tumor-resident plasmacytoid dendritic cells in humanized mouse models. Front Immunol. 2020;11:2082

51. Strowig T, Chijioke O, Carrega P, Arrey F, Meixlsperger S, Rämer PC, et al. Human NK cells of mice with reconstituted human immune system components require preactivation to acquire functional competence. Blood. 2010;116:4158-67.

52. Lang J, Kelly M, Freed BM, McCarter MD, Kedl RM, Torres RM, et al. Studies of lymphocyte reconstitution in a humanized mouse model reveal a requirement of T cells for human B cell maturation. Jl. 2013;190:2090-101.

53. Kovats $S$. Estrogen receptors regulate innate immune cells and signaling pathways. Cell Immunol. 2015;294:63-9.

54. Huang H, Zhou J, Chen H, Li J, Zhang C, Jiang X, et al. The immunomodulatory effects of endocrine therapy in breast cancer. J Exp Clin Cancer Res. 2021:40:19.

55. Choi B, Chun E, Kim M, Kim S-T, Yoon K, Lee K-Y, et al. Human B cell development and antibody production in humanized NOD/SCID/LL-2Rynull (NSG) mice conditioned by busulfan. J Clin Immunol. 2011;31:253-64.

56. Robert-Richard E, Ged C, Ortet J, Santarelli X, Lamrissi-Garcia I, de Verneuil $\mathrm{H}$, et al. Human cell engraftment after busulfan or irradiation conditioning of NOD/SCID mice. Haematologica. 2006;91:1384

57. Rongvaux A, Willinger T, Martinek J, Strowig T, Gearty SV, Teichmann LL, et al. Development and function of human innate immune cells in a humanized mouse model. Nat Biotechnol. 2014;32:364-72.
58. Yoshihara S, Li Y, Xia J, Danzl N, Sykes M, Yang Y-G. Posttransplant hemophagocytic lymphohistiocytosis driven by myeloid cytokines and vicious cycles of T-cell and macrophage activation in humanized mice. Front Immunol. 2019;10:186.

59. Meraz IM, Majidi M, Meng F, Shao R, Ha MJ, Neri S, et al. An improved patient-derived xenograft humanized mouse model for evaluation of lung cancer immune responses. Cancer Immunol Res. 2019;7:1267-79.

60. Turner NC, Swift C, Kilburn L, Fribbens C, Beaney M, Garcia-Murillas I, et al. ESR1 mutations and overall survival on fulvestrant versus exemestane in advanced hormone receptor-positive breast cancer: a combined analysis of the phase III SoFEA and EFECT trials. Clin Cancer Res. 2020;26:5172-7.

61. Schupp J, Krebs FK, Zimmer N, Trzeciak E, Schuppan D, Tuettenberg A. Targeting myeloid cells in the tumor sustaining microenvironment. Cell Immunol. 2019;343:103713.

62. Kitamura T, Qian B-Z, Pollard JW. Immune cell promotion of metastasis. Nat Rev Immunol. 2015;15:73-86.

63. Davidov V, Jensen G, Mai S, Chen S-H, Pan P-Y. Analyzing one cell at a TIME: analysis of myeloid cell contributions in the tumor immune microenvironment. Front Immunol. 2020;11:1842.

64. Cha YJ, Koo JS. Role of tumor-associated myeloid cells in breast cancer. Cells. 2020;9:1785

65. Dustin D, Gu G, Beyer AR, Herzog SK, Edwards DG, Lin H, et al. RON signalling promotes therapeutic resistance in ESR1 mutant breast cancer. Br J Cancer. 2021;124:191-206.

66. Salguero G, Daenthanasanmak A, Münz C, Raykova A, Guzmán CA, Riese $P$, et al. Dendritic cell-mediated immune humanization of mice: implications for allogeneic and xenogeneic stem cell transplantation. J. 2014;192:4636-47.

67. Park N, Pandey K, Chang SK, Kwon A-Y, Cho YB, Hur J, et al. Preclinical platform for long-term evaluation of immuno-oncology drugs using hCD34+ humanized mouse model. J Immunother Cancer. 2020;8:1513.

68. Haanen JBAG. Converting cold into hot tumors by combining immunotherapies. Cell. 2017:170:1055-6.

69. Galon J, Bruni D. Approaches to treat immune hot, altered and cold tumours with combination immunotherapies. Nat Rev Drug Discov. 2019;18:197-218.

70. Duan $\mathrm{Q}$, Zhang $\mathrm{H}$, Zheng J, Zhang L. Turning cold into hot: firing up the tumor microenvironment. Trends Cancer. 2020;6:605-18.

71. Zhang J, Endres S, Kobold S. Enhancing tumor T cell infiltration to enable cancer immunotherapy. Immunotherapy. 2019;11:201-13.

72. Karkeni E, Morin SO, Bou Tayeh B, Goubard A, Josselin E, Castellano R, et al. Vitamin D controls tumor growth and CD8+ T cell infiltration in breast cancer. Front Immunol. 2019;10:1307.

73. Ribas A, Dummer R, Puzanov I, VanderWalde A, Andtbacka RHI, Michielin $\mathrm{O}$, et al. Oncolytic virotherapy promotes intratumoral T cell infiltration and improves anti-PD-1 immunotherapy. Cell. 2017;170:1109-1119.e10.

74. Ribas A, Dummer R, Puzanov I, VanderWalde A, Andtbacka RHI, Michielin $\mathrm{O}$, et al. Oncolytic virotherapy promotes intratumoral $\mathrm{T}$ cell infiltration and improves anti-PD-1 immunotherapy. Cell. 2018;174:1031-2.

75. Drake AC, Chen Q, Chen J. Engineering humanized mice for improved hematopoietic reconstitution. Cell Mol Immunol. 2012;9:215-24.

76. Verma B, Wesa A. Establishment of humanized mice from peripheral blood mononuclear cells or cord blood CD34+ hematopoietic stem cells for immune-oncology studies evaluating new therapeutic agents. Curr Protoc Pharmacol. 2020. https://doi.org/10.1002/cpph.77.

77. Sontas HB, Dokuzeylu B, Turna O, Ekici H. Estrogen-induced myelotoxicity in dogs: a review. Can Vet J. 2009;50:1054-8.

78. Kociba GJ, Caputo CA. Aplastic anemia associated with estrus in pet ferrets. J Am Vet Med Assoc. 1981;178:1293-4.

\section{Publisher's Note}

Springer Nature remains neutral with regard to jurisdictional claims in published maps and institutional affiliations. 